\title{
Investigating the Causes of Nursing Errors and Its Reduction Countermeasures in Recent Studies: A Review
}

\author{
Ali salehi sahlabadi ${ }^{\text {iD }}$, Afsaneh $\operatorname{Riazat}^{2}{ }^{\text {iD }}$, Sheari Suri $^{2}$ iD, $\operatorname{Negar~Saffarinia2~}^{2}$ (D), \\ Zahra Damerchi $^{2}$ iD, Mostafa Pouyakian ${ }^{1}$ iD *
}

1. Assistant Professor, Department of Occupational Health and Safety Engineering, School of Public Health and Safety, Shahid Beheshti Univeristy of Medical Sciences, Tehran, Iran

2. Master of Occupational Health and Safety Engineering, Department of Occupational Health and Safety Engineering, School of Public Health and Safety, Shahid Beheshti Univeristy of Medical Sciences, Tehran, Iran

\begin{tabular}{|c|c|}
\hline Article Info & ABSTRACT \\
\hline $\begin{array}{l}\text { Received: 2020/06/06; } \\
\text { Accepted: 2020/07/04; } \\
\text { ePublished: 2020/07/04 }\end{array}$ & $\begin{array}{l}\text { Background and Objectives: Nursing errors are a serious threat to patient safety, } \\
\text { which can lead to increased public concern and distrust of recipients of health care } \\
\text { services and refusal to undergo treatment. Therefore, the present study examines types } \\
\text { of causes of nurses' errors, reasons for not reporting them and ways to reduce errors. }\end{array}$ \\
\hline $\begin{array}{l}\text { doi } 10.30699 / \text { jergon.8.1.74 } \\
\text { Use your device to scan } \\
\text { and read the article online }\end{array}$ & $\begin{array}{l}\text { Methods: The present study was a narrative review study of English and Persian } \\
\text { articles on nurses' errors in the period (2008-2018) and was done in 2019. Articles were } \\
\text { searched in three internal databases such as SID, Magiran and Iran Medex and five } \\
\text { external databases of Google Scholar, PubMed, Scopus, Science Direct, and Springer. }\end{array}$ \\
\hline 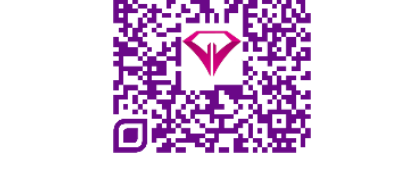 & $\begin{array}{l}\text { Results: Most nursing errors were in the form of functional errors. Risk factors were } \\
\text { divided into nurse, organization, ward, and patient-related error factors. The reasons for } \\
\text { nurses' failure to report errors include professional reputation and legal problems. Error } \\
\text { reduction strategies are such as nursing education and management controls. }\end{array}$ \\
\hline $\begin{array}{l}\text { Corresponding Author } \\
\text { Mostafa Pouyakian } \\
\text { Department of occupational } \\
\text { health and safety engineering, } \\
\text { School of Public Health and } \\
\text { Safety, Shahid Beheshti } \\
\text { Univeristy of Medical Sciences, } \\
\text { Tehran Iran }\end{array}$ & $\begin{array}{l}\text { Conclusion: Nursing errors have been studied in various ways. These studies are } \\
\text { not only aimed at identifying nurses' errors, but also to enhance knowledge and } \\
\text { knowledge about the possible causes and preventive factors. The benefits of this view } \\
\text { of the articles lead to the provision of appropriate health care services, proper } \\
\text { planning for hospitals by managers, and the advancement of nursing education. } \\
\text { However, fewer studies have used modern methods of hazard identification. }\end{array}$ \\
\hline $\begin{array}{l}\text { Email: } \\
\text { pouykian@sbmu.ac.ir }\end{array}$ & $\begin{array}{l}\text { Keywords: Nursing error, Cause, Non-reporting, Guidelines, Patient safety, } \\
\text { Review }\end{array}$ \\
\hline
\end{tabular}

How to Cite This Article:

Salehi Sahlabadi A, Riazat A, Soury S, Saffarinia N, Damerchi Z, Pouyakian M. Investigating the Causes of Nursing Errors and Its Reduction Countermeasures in Recent Studies: A Review. Iran J Ergon. 2020; 8 (1) :74-88 
مرور روايتى بر علل خطاهاى يرستارى و راهكارهاى كاهش آن در مطالعات كذشته

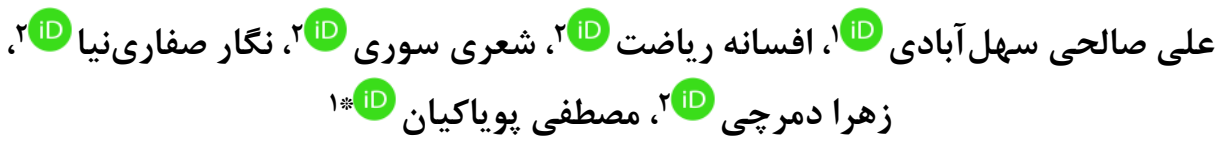

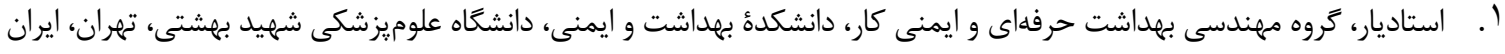

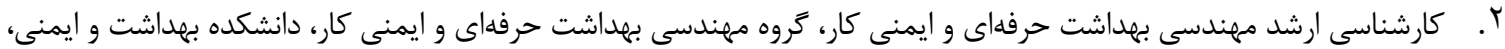

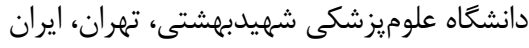

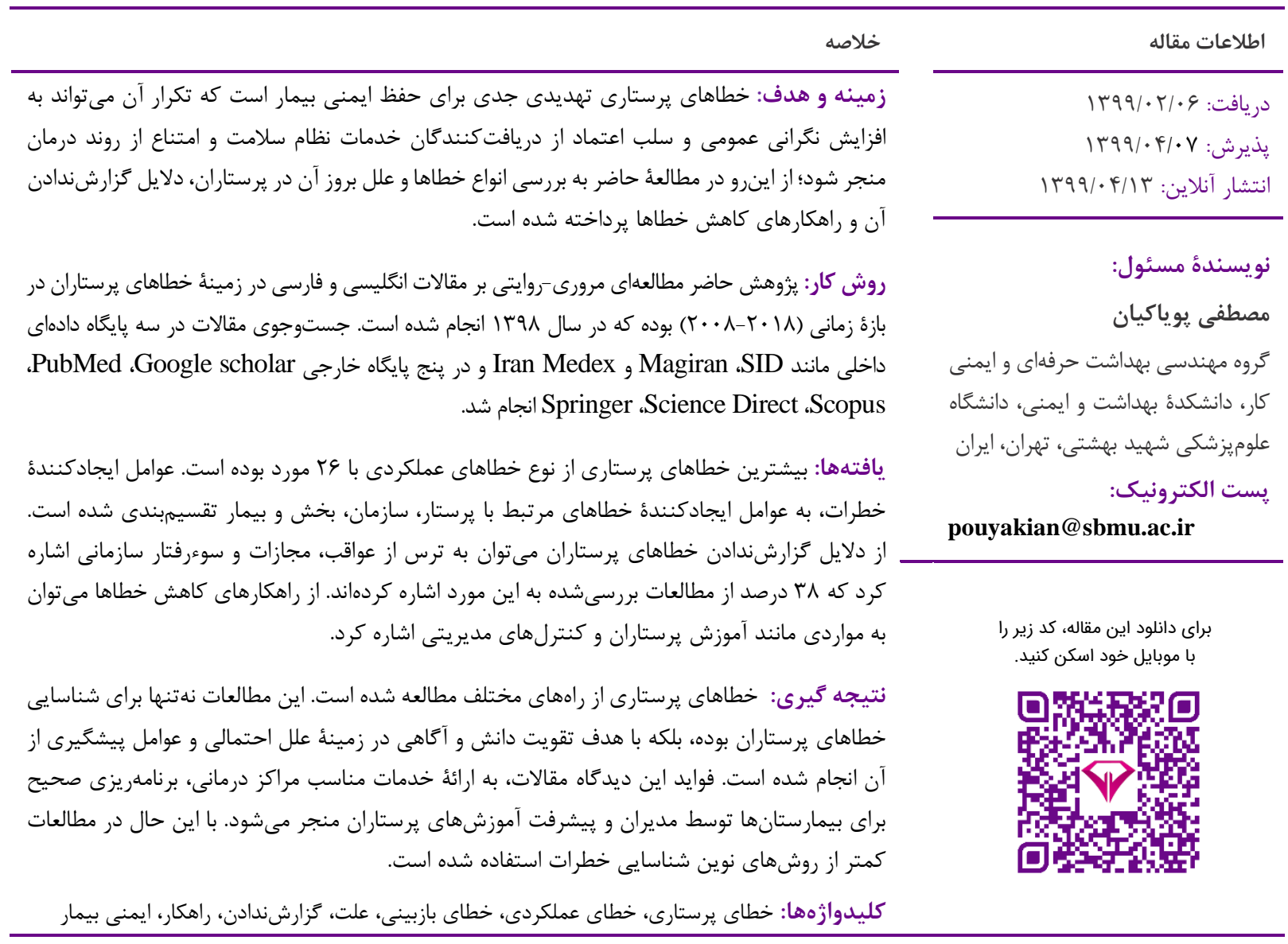

يزشكى مىشود [9]. نرخ بروز اشتباهات در سيستمهاى

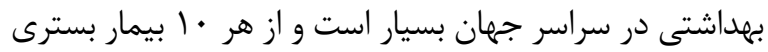
يك مورد بر سلامتى آنها تأثير مى حذارد. علاوه بر اين، تقريباً

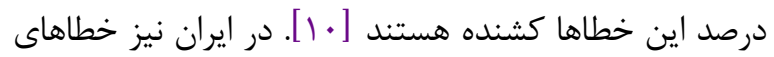
يزشكى و محكوميت اله درصد از يرستاران در يروندههاى

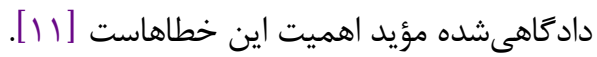
اصطلاح خطا شامل انحراف از صحت و قدم در مسير اهميت اندان اشتباه است [ [1]]. Lewis و همكاران مشاركت يرستاران در
ايمنى بيمار جزء كليدى كيفيت مراقبت [ب، ا] و نخرانى اصلى هر سيستم مراقبت بهداشتى است [ه-ب]. خطا نيز بخش ئش

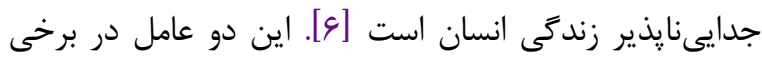
مشاغل حساس مانند يزشكى و ويرستارى كه با حيات بيمار ارتباط دارد، عواقب جبراننايذيرى بهدنبال دارند. همجنين خطاهاى يرستارى مىتواند موجب افزايش نخرانى عمومى

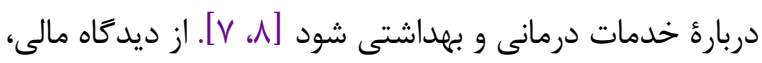
سالانه در ايالاتمتحده بيش از IV ميليارد دلار صرف خطاهاى 
على صالحى سهل آبادى و همكاران ا بررسى تأثير حمايت سازمانى ادراكشده در شكستن سكوت سازمانى با نقش ميانجى تعهد عاطفى

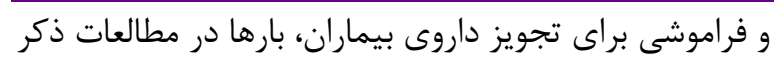

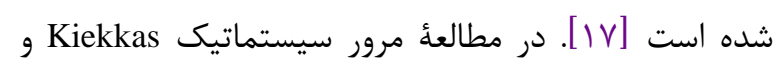

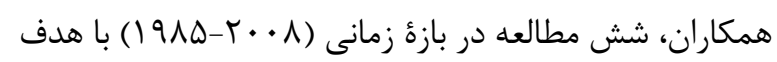

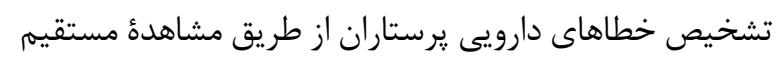

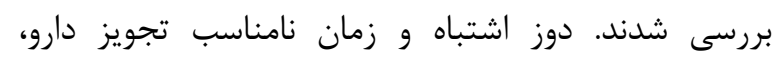

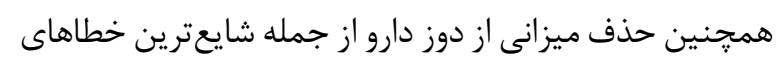

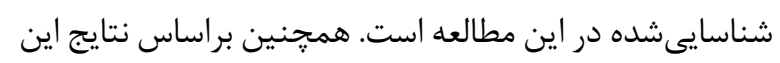
مطالعه، تشخيص عوامل مؤثر بر خطاهاى دارويى غيرقابل

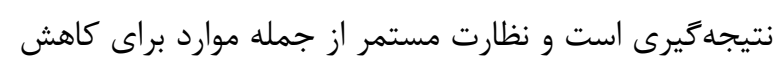

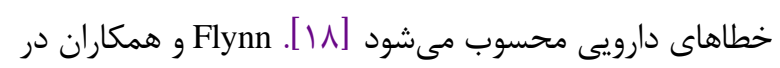

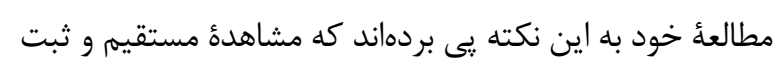

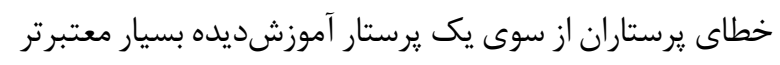

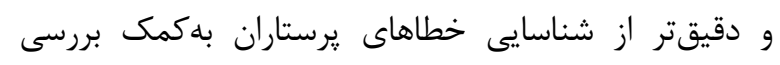

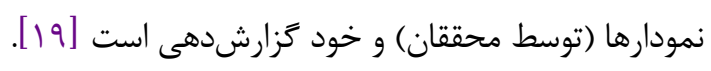

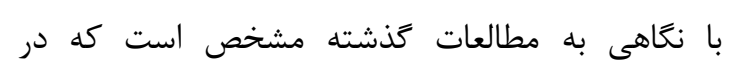

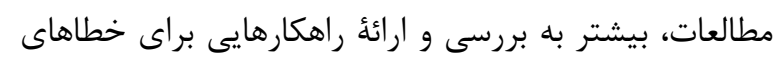

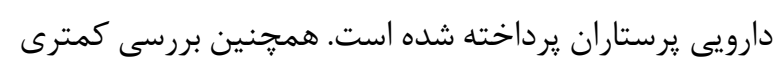

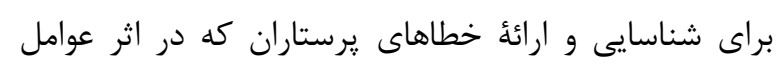

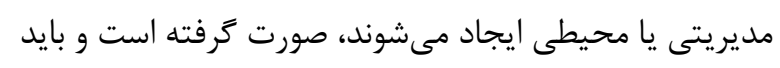

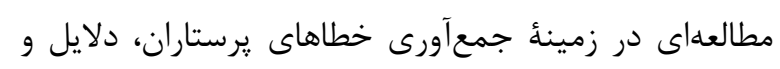

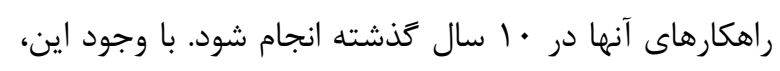

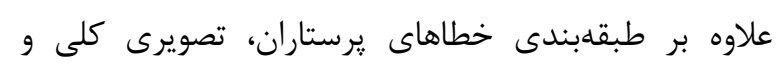

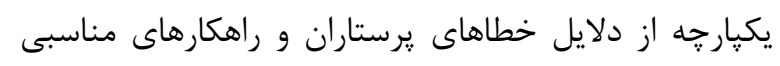

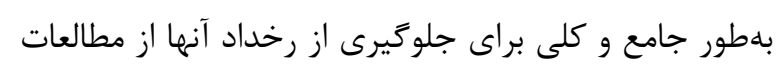

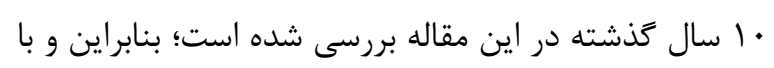

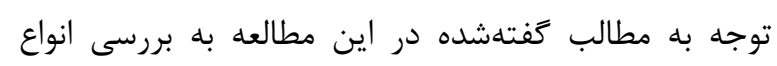

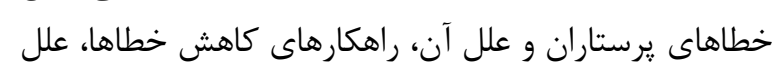

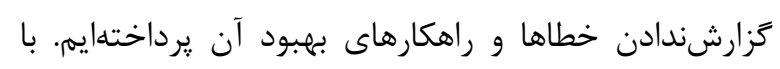

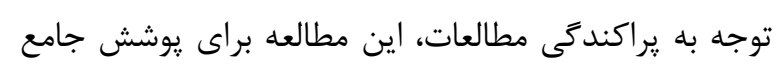
مباحث نامبرده به جمعبندى آنها يرداخته است.

\section{روش كار}

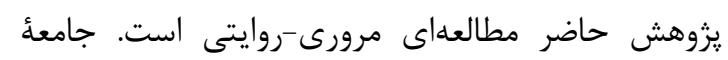

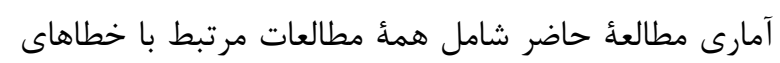

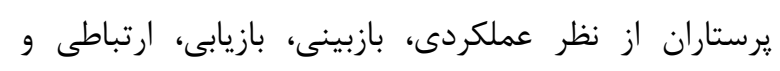

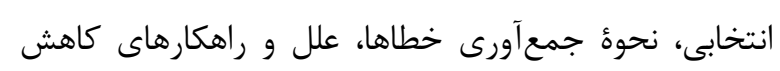

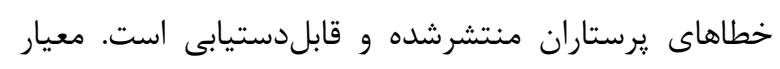

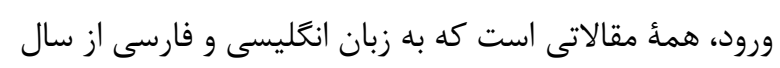

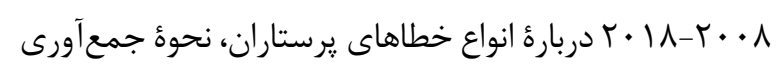

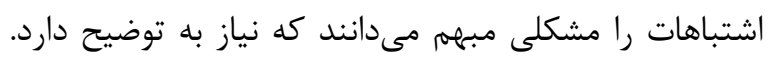

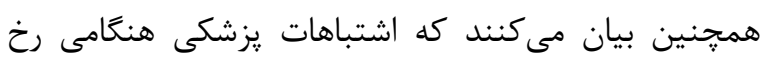

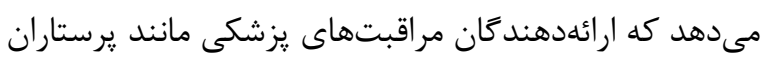

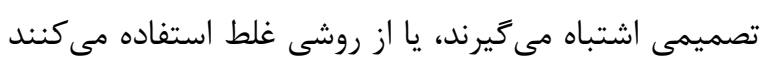

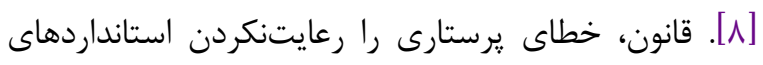

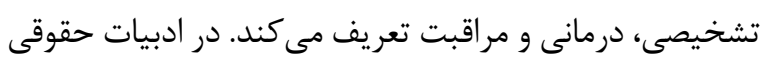

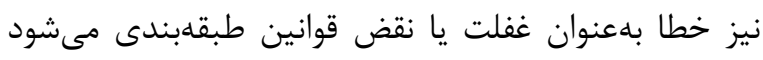

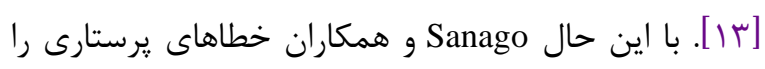

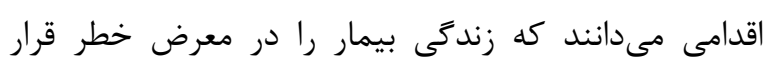

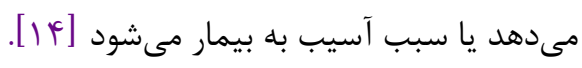

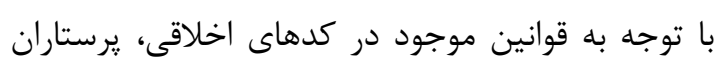

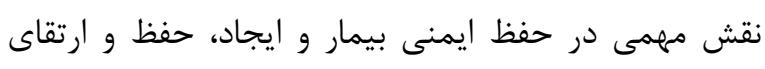

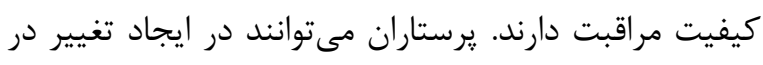

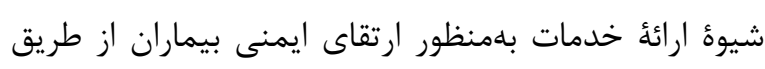

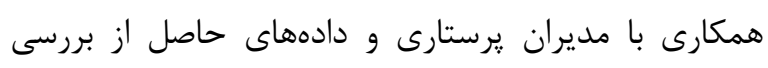

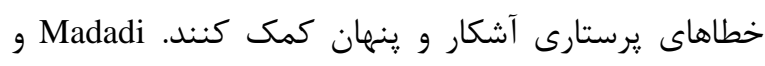
Jaafaripooyan

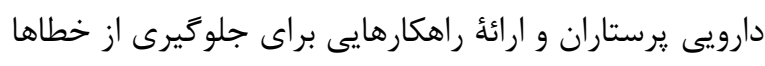

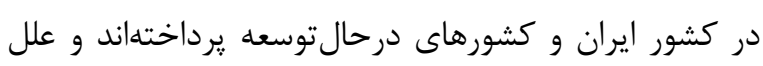

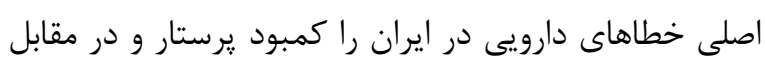

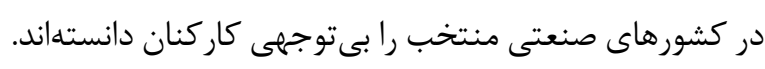

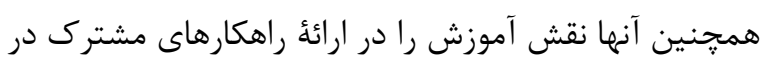

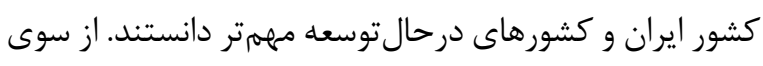

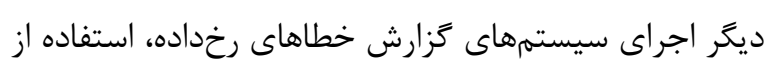

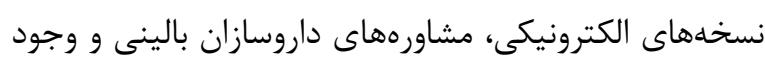

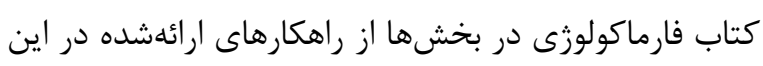

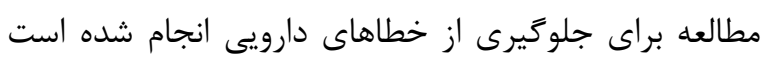

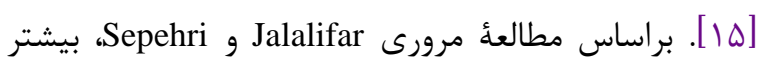

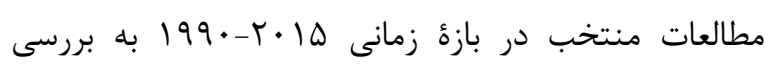
خطاهاى يرستاران هنكام تجويز دارو يرداختهاند، اما مطالعات

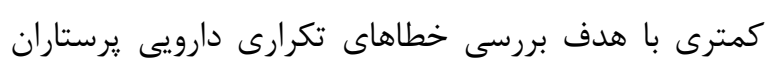

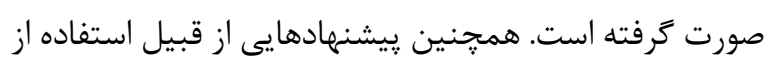
سيستمهاى كامييوترى و ديكر سيستههاى الكترونيكى براى

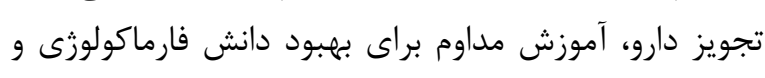
كاهش خطاهاى دارويى در بيمارستانها در مطالعأ مذأ مذكور

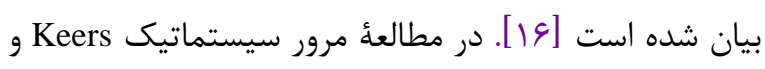

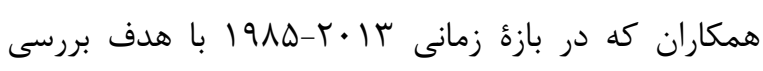

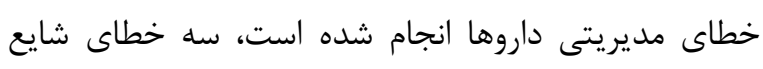

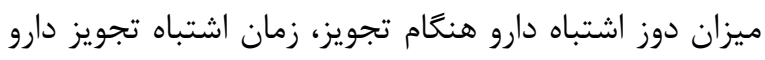




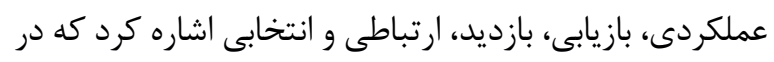

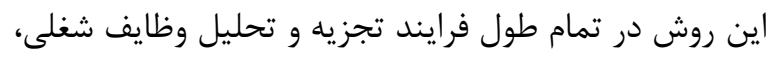

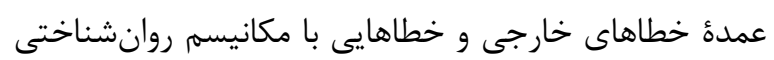

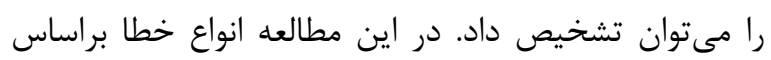
طبقهبندى روش SHERPA مطالعه شده است.

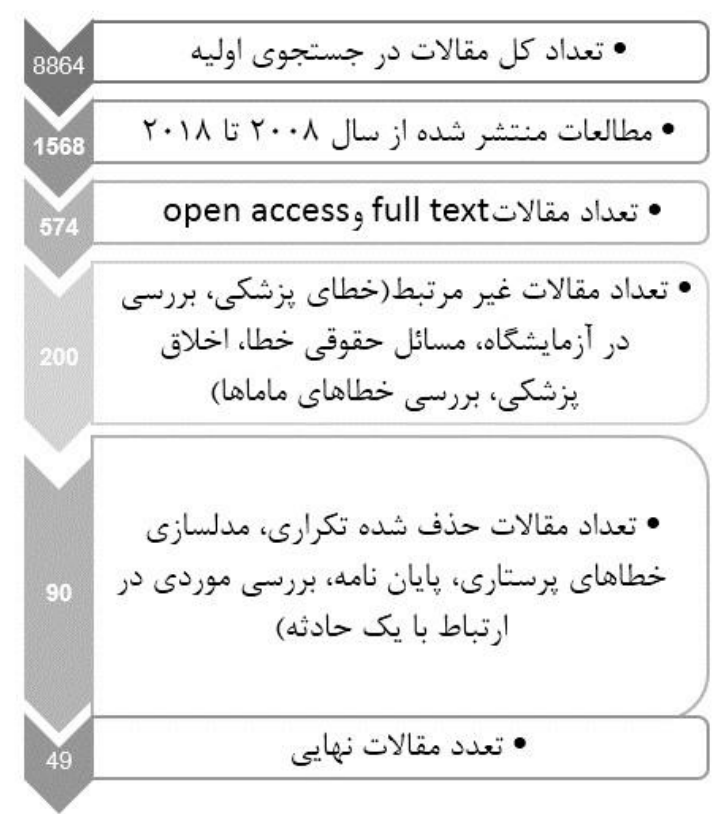

شكل ا. نحوهُ انتخاب مقالات در يايكاههاى داده

يافته ها جدول 1 فهرست مطالعات نهايى انتخابشده براساس نام نويسندكان مقالات، سال و روش جمعآ آورى دادهها آمده

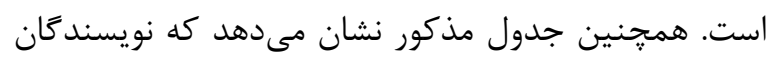

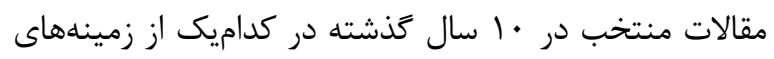

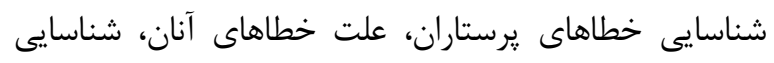

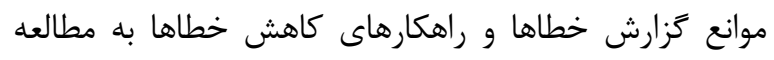

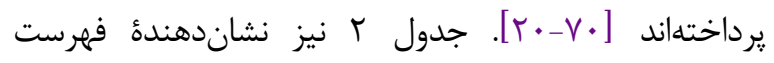

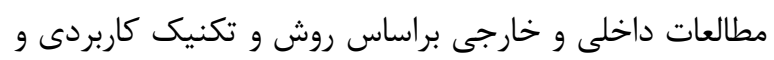
تعداد مقالات بررسىشده به روش يا تكنيكهاى مذكور است.
اطلاعات، علل و راهكارهاى كاهش مرتبط با آنها به خاب

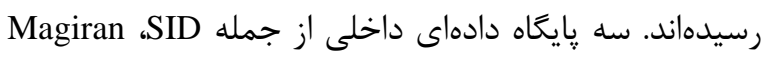
و Iran Medex با كليدوازههاى فارسى خطاى انسانى و خطاى آنس

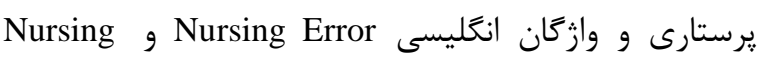
دuman error شاند Science Direct Scopus ،PubMed شدهاند. كليدوازمهاى انتخابشده بهدليل تمركز بيشتر بر

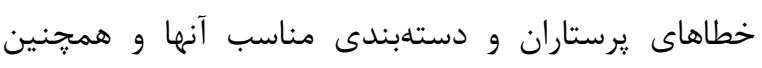
بهدليل همخوانى با هدف مطالعئ حاضر بوده است. در ابتدان

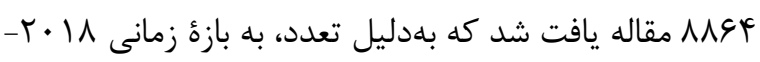

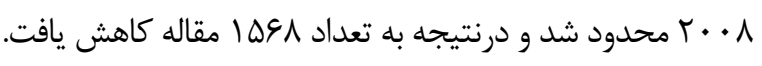

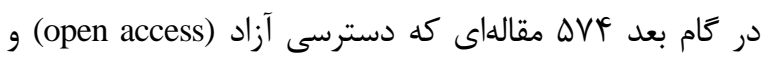

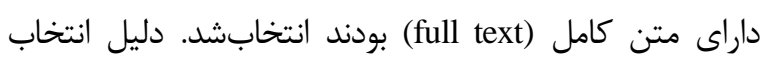
مقالات full text و نيز اهميت دسترسى به جزئيات اشاره شده در متن مقالات بود. همجنين غيرمرتبطبودن (خطاى يزشكى، بررسى در آزمايشكاه، مسائل

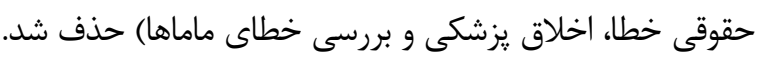

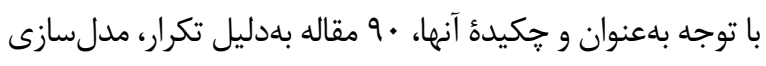

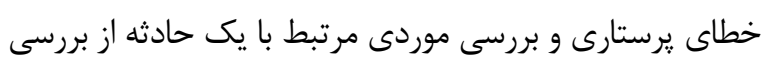

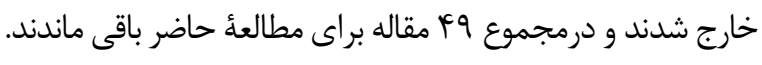
شكل ا فرايند كامل انتخاب مقالات را نشان مى دمدهد.

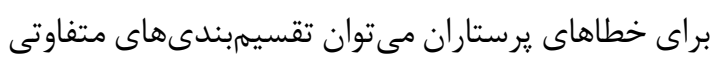

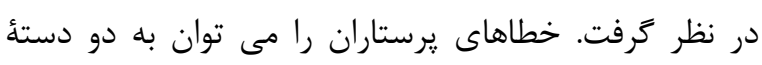

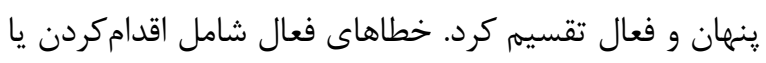

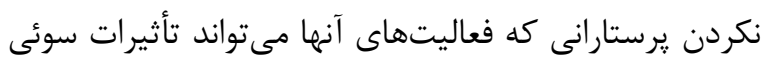

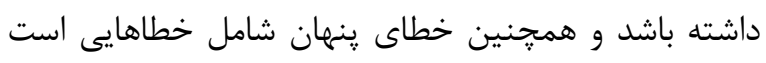

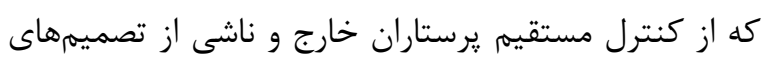

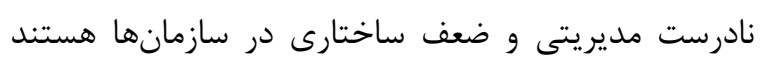

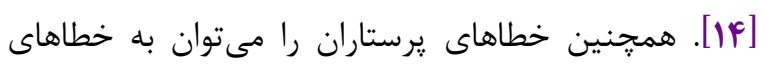

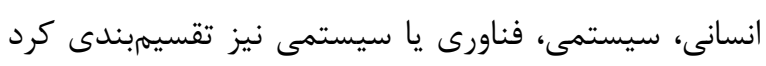

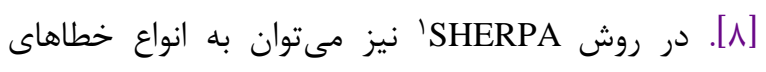

جدول ا. فهرست مطالعات بر اساس نويسنده، سال، روش جمع آورى دادهها و زمينهُ اصلى مطالعات براساس شناسايى، علل، موانع تزارشدهىى و راهكارهاى كاهش خطاها

\begin{tabular}{|c|c|c|c|c|c|c|c|}
\hline كاهش راهكارهاى & خزَارش & علر خطى & شناسايى & روش جمعآورى & سال & نويسنده & رديف \\
\hline$*$ & & & & پرسشنامه & $r \cdot M$ & Shali et al. & 1 \\
\hline
\end{tabular}

1. A systematic human error reduction and prediction approach 
على صالحى سهل آبادى و همكاران | بررسى تأثير حمايت سازمانى ادراكشده در شكستن سكوت سازمانى با نقش ميانجى تعهد عاطفى

\begin{tabular}{|c|c|c|c|c|c|c|c|}
\hline كاهش راهكارهاى & خزازأع & علا خطى & شناسايى & روش جمعآورى & 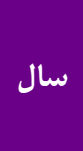 & نويسنده & رديف \\
\hline & & & $*$ & يرسشنامه & $r \cdot 11$ & Sharbaafchi zadeh et al. & $r$ \\
\hline & & & $*$ & يرسشنامه & $r \cdot 11$ & Azarabad et al. & r \\
\hline & & & $*$ & SHERPA & $r \cdot 1 \Lambda$ & Ghiyasi et al. & $\varepsilon$ \\
\hline \multirow[t]{2}{*}{$*$} & & & & يرسشنامه & $r \cdot 11$ & Chen et al. & 0 \\
\hline & & $*$ & & يرسشنامه & $r \cdot 11$ & Kohan et al. & 7 \\
\hline \multirow[t]{2}{*}{$*$} & & $*$ & $*$ & FMEA & $r \cdot I V$ & Askari et al. & $\checkmark$ \\
\hline & & $*$ & $*$ & TRACer & $r \cdot I V$ & Babaei pouya et al. & $\wedge$ \\
\hline \multirow[t]{3}{*}{$*$} & & $*$ & & SHERPA & $r+I V$ & Mirzae Aliabadi et al. & $q$ \\
\hline & & $*$ & & جكليست & $r+I V$ & Foo et al. & $1+$ \\
\hline & & $*$ & & קیرسشليست و & $r \cdot I V$ & Alemu et al. & 11 \\
\hline \multirow[t]{2}{*}{$*$} & $*$ & & $*$ & 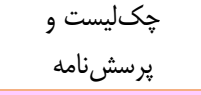 & $r \cdot I V$ & Fathi et al. & it \\
\hline & & $*$ & * & مصاحبه & $r \cdot I V$ & Ajri Khameslou et al. & "ו \\
\hline \multirow[t]{3}{*}{$*$} & $*$ & $*$ & $*$ & يرسشنامه & $r \cdot 19$ & Ebrahimipour et al. & $1 \varepsilon$ \\
\hline & $*$ & & $*$ & يرسشنامه & $r+19$ & Ghorbanpour Diz et al. & 10 \\
\hline & $*$ & & & مصاحبه & $r+19$ & Peyrovi et al. & 17 \\
\hline$*$ & $*$ & $*$ & & NPSA & $r \cdot 19$ & Adibi et al. & iv \\
\hline$*$ & & $*$ & $*$ & يرسشنامه & $r \cdot 19$ & Winsett et al. & 11 \\
\hline$*$ & & $*$ & & يرسشنامه & $r \cdot 19$ & Zeighami et al. & 19 \\
\hline \multirow[t]{4}{*}{$*$} & & & & - & $r \cdot 19$ & Bravo et al. & $r+$ \\
\hline & $*$ & & & مصاحبه & $r \cdot 19$ & Samsiah et al. & r) \\
\hline & & $*$ & & يرسشنامه & $r+19$ & Weaver et al. & r \\
\hline & & $*$ & & - & $r \cdot 19$ & Morelock et al. & r \\
\hline \multirow[t]{3}{*}{$*$} & $*$ & & & يرسشنامه & $r \cdot 19$ & Shahabi et al. & $r \varepsilon$ \\
\hline & & $*$ & * & يرسشنامه & $r \cdot 19$ & Saki et al. & ro \\
\hline & & & $*$ & يرسشنامه & $r \cdot 19$ & Rahimi et al. & r \\
\hline \multirow[t]{3}{*}{$*$} & & $*$ & $*$ & بررسى رويداد & $r \cdot 10$ & Wan et al. & rV \\
\hline & & $*$ & * & SPR-H & $r+10$ & Mohammadfam et al. & $r \wedge$ \\
\hline & & $*$ & * & نظرسنجى & $r \cdot 10$ & Roth et al. & rq \\
\hline \multirow[t]{3}{*}{$*$} & & & & 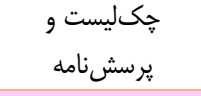 & $r \cdot 10$ & Feleke et $a l$. & r. \\
\hline & $*$ & & & يرسشنامه & $r \cdot 10$ & Nwozichi et al. & ו \\
\hline & & & & קكليست & $r \cdot 10$ & Bozorgzad et al. & r \\
\hline
\end{tabular}




\begin{tabular}{|c|c|c|c|c|c|c|c|}
\hline كاهش راهكارهاى & خز موارش & علل خطى على & شناسايى & روش جمعآورى & 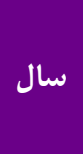 & نويسنده & رديف \\
\hline & * & & & يرسشنامه & $r \cdot 10$ & Nouhi et al. & 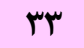 \\
\hline \multirow[t]{2}{*}{$*$} & & & & تشكيل كميته & $r \cdot 10$ & Wu et al. & ع \\
\hline & & & & يرسشنامه & $r+10$ & ahangarzade rezaie et al. & ro \\
\hline \multirow[t]{3}{*}{$*$} & & $*$ & $*$ & CREAM & $r+14$ & Mohammadfam et al. & 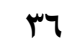 \\
\hline & & $*$ & & يرسشنامه & $r \cdot 1 f$ & Hesari et al. & rv \\
\hline & & & $*$ & يرسشنامه & $r+14$ & Zhu et al. & щ^ \\
\hline \multirow[t]{3}{*}{$*$} & & & & يرسشنامه & $r \cdot 1 f$ & Nouhi et al. & rq \\
\hline & & & & يرسشنامه & $r \cdot 1 r$ & Pazokian et al. & $\varepsilon$ \\
\hline & & * & * & يرسشنامه & $r \cdot 1 r$ & Habermann et al. & $\varepsilon 1$ \\
\hline \multirow[t]{5}{*}{$*$} & & $*$ & $*$ & يرسشنامه & $r \cdot 1 r$ & Rahimian Boogar et al. & $\varepsilon r$ \\
\hline & & & & SHERPA & $r \cdot 1 r$ & Kermani et al. & س \\
\hline & & * & * & يرششنامه & $r \cdot 1 r$ & Mirzaei et al. & $\varepsilon \varepsilon$ \\
\hline & * & $*$ & $*$ & يرششنامه & $r+i r$ & Bagaei et al. & 乏o \\
\hline & & $*$ & & يرسشنامه & $r \cdot i r$ & Salavati et al. & $\varepsilon 7$ \\
\hline$*$ & & * & & مصاحبه & $r \cdot 11$ & Wilkinson et al. & $\varepsilon V$ \\
\hline$*$ & & $*$ & & يرسشنامه & $r \cdot 1 \cdot$ & Eslamian et al. & $\varepsilon \wedge$ \\
\hline$*$ & & & $*$ & - & $r+. q$ & Green et al. & $\varepsilon q$ \\
\hline
\end{tabular}

بازبينى، ارتباطى، بازيابى و انتخابى است. همجنين شكل r

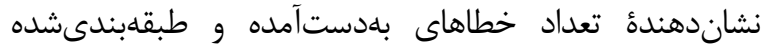
بهمك روش SHERPA از بررسى مقالات مختلف است. Ajri-Khameslou خطاى يرستاران در بخش مراقبت ويزه يرداختهاند [FF]. درباره علل خطا مىتوان به جهار طبقهُ اصلى اشاره كرد: عوامل

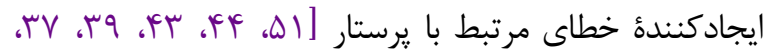

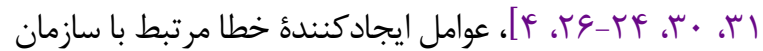

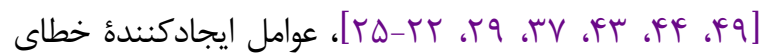
مرتبط با مراقبتهاى ويزه و بخش [?q

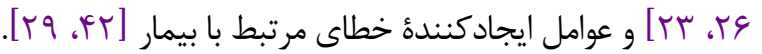
جهار طبقهُ اصلى عوامل ايجادكننده خطاها به همراه زيرطبقات آنها در جدول أ ارائه شده است.
براساس جدول r، در ها مطالعه از اس مطالعهُ داخل كشور و 11 مطالعه از مطالعات خارجى، خطاهاى يرستاران بلوسيلة يرسشنامه بررسى شده است. همجنين روشهاى مختلفى براى شناسايى خطاى يرستاران در مطالعات داخلى برخلاف مطالعات خارجى استفاده شده است. در مطالعهُ حاضر نيز خطاهاى يرستاران براساس روش SHERPA به ينج دسته خطاهاى

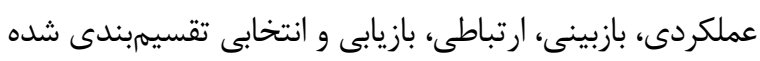

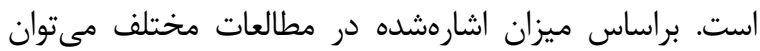

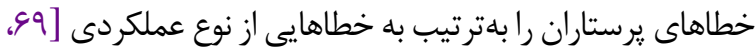
F

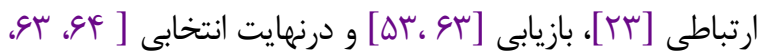

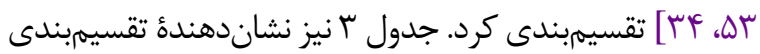
خطاهاى ذكرشده در مقالات منتخب به خطاهاى عملكردى، 
على صالحى سهل آبادى و همكاران | بررسى تأثير حمايت سازمانى ادراكشده در شكستن سكوت سازمانى با نقش ميانجى تعهد عاطفى

\section{تعداد مقالات}

\begin{tabular}{|c|c|c|}
\hline 10 & يرسشنامه & \multirow{10}{*}{ مطالعات داخل كشور (آ⿱) } \\
\hline r & مصاحبه & \\
\hline$r$ & SHERPA & \\
\hline 1 & جكليست و پرسشنامه & \\
\hline 1 & 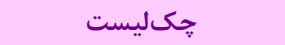 & \\
\hline 1 & Cream & \\
\hline 1 & FMEA & \\
\hline 1 & Tracer & \\
\hline 1 & NPSA & \\
\hline 1 & SPRH & \\
\hline 11 & يرسشنامه & \multirow{7}{*}{ مطالعات خارج از كشور (1) } \\
\hline$r$ & مصاحبه & \\
\hline r & جك ليست و يرسشنامه & \\
\hline 1 & جكليست & \\
\hline 1 & بر برى رويداد & \\
\hline 1 & تشكيل كميته & \\
\hline 1 & نظرسنجى & \\
\hline
\end{tabular}

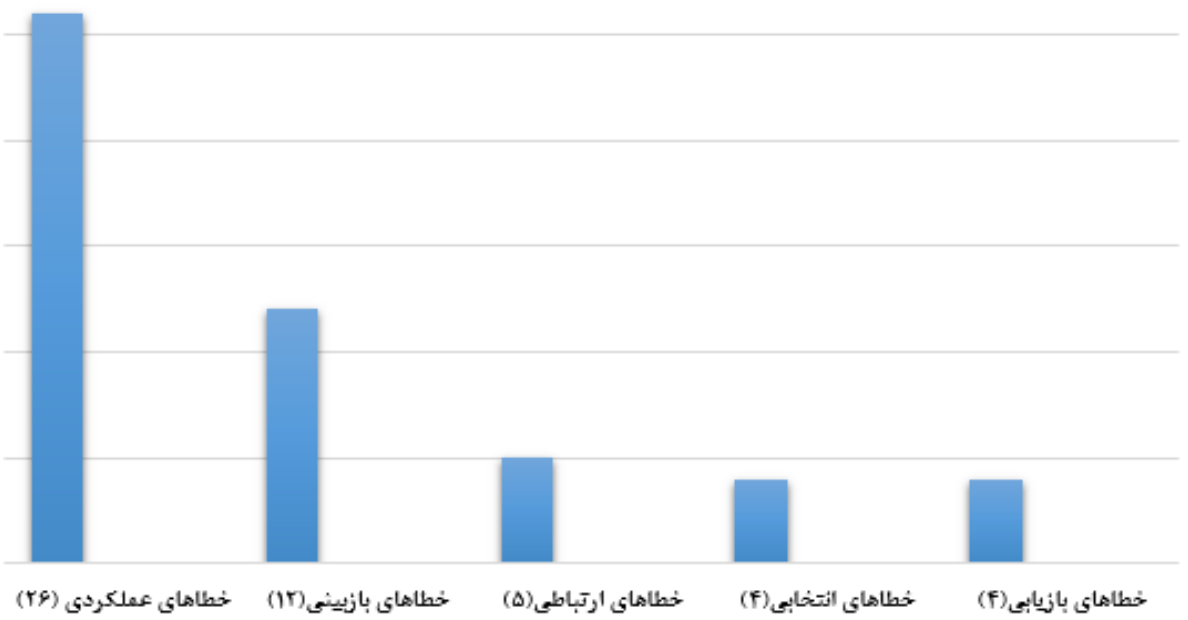

شكل r. خطاهاى طبقلبندى شده بهوسيلئ روش SHERPA از بررسى مقالات مختلف 


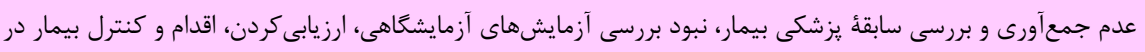

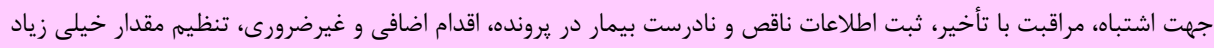

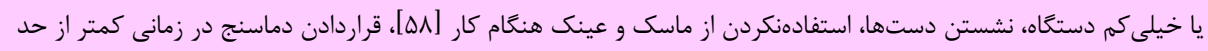

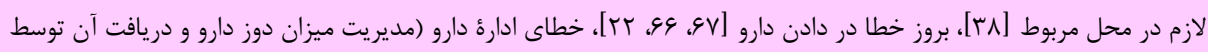

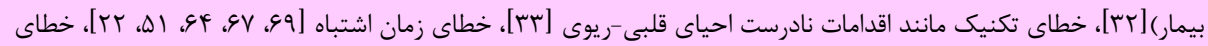

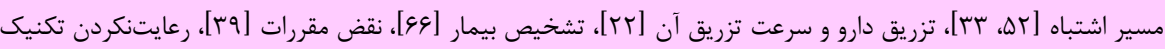

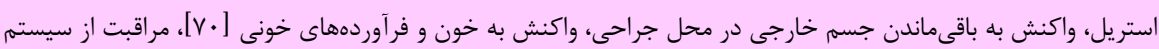

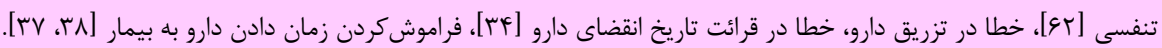

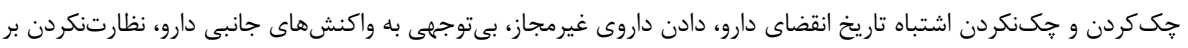

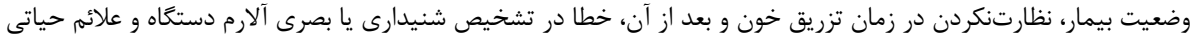

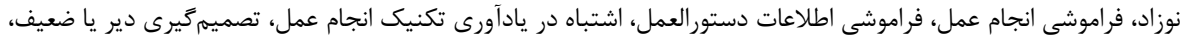

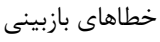

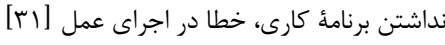

اقدامات فورى براى ديسريتمى، انجام خطا در اقدامات اوليئ احيا، اعلام كد و شروع اقدامات احياى قلب و ريه، اعلام كد اشتباه [هr]

خطاهاى بازيابى

ناخوانابودن دستور يزشك، مداخلات زودهنكام يا ديرتر، روابط ميان يزشك و يرستار، خطا در نوشتن كزارش بيمار بعد از هر بار

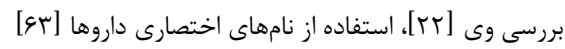

خطاهاى ارتباطى

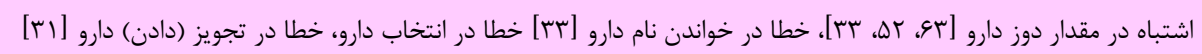

خطاهاى انتخابى

جدول F. جهار طبقة اصلى عوامل ايجادكننده خطاها

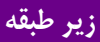

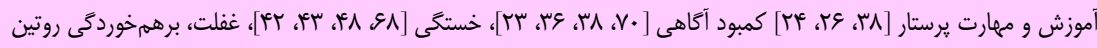

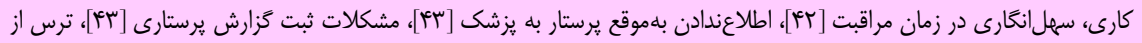

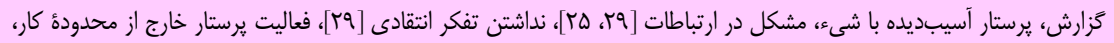

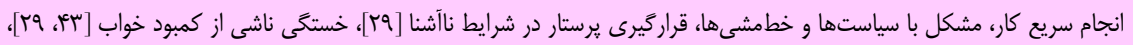

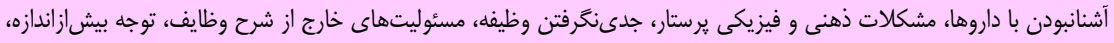

عوامل ايجادكننده خطا مرتبط با يرستار

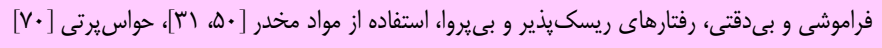

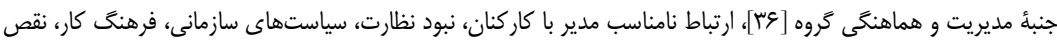

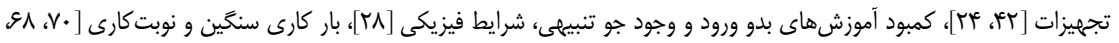

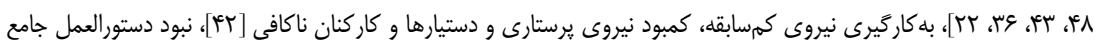

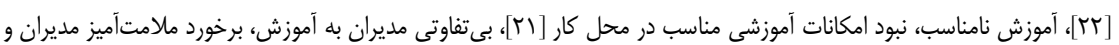

عوامل ايجادكننده خطا مرتبط با سازمان

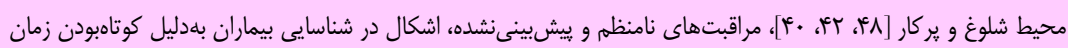

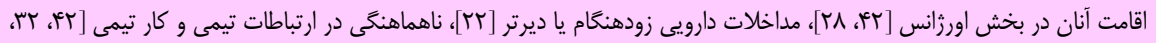

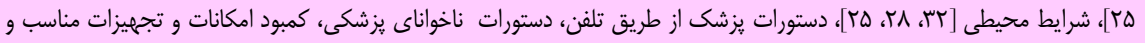
خرابى دستخاهها [FV

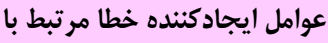

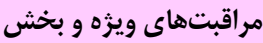

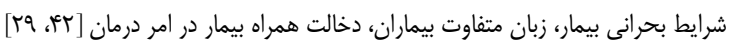

عوامل ايجادكننده خطاى مرتبط با 
على صالحى سهل آبادى و همكاران | بررسى تأثير حمايت سازمانى ادراكشده در شكستن سكوت سازمانى با نقش ميانجى تعهد عاطفى

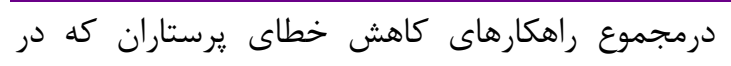
مقالات ارائه شدهاند شامل موارد زير است:

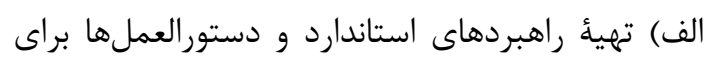

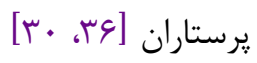

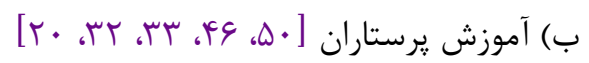

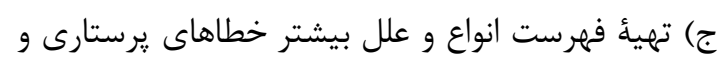

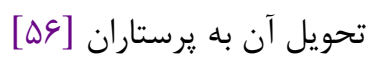

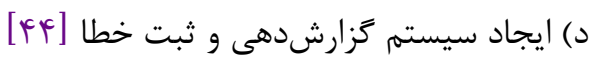

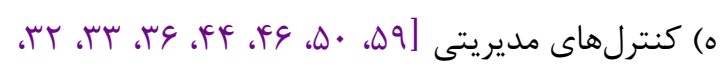
Tht ra و) ايجاد فرهنَ يادكيرى از خطا و ريشخَيرى از آن

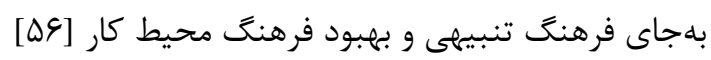

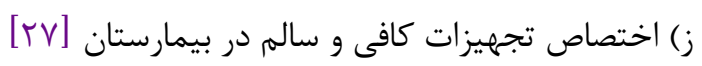

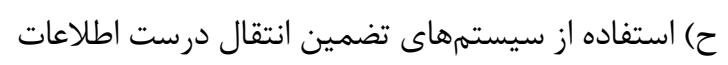

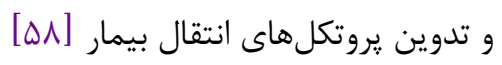

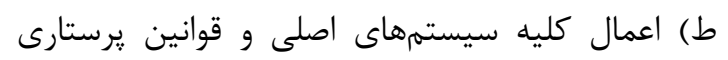

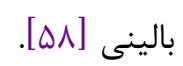

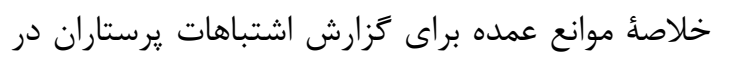
مطالعات عوامل زير شناخته شدهاند:

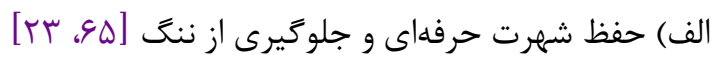

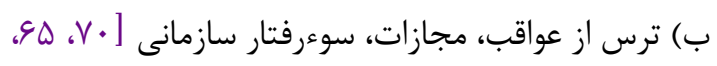

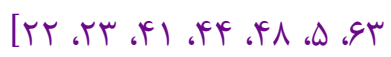

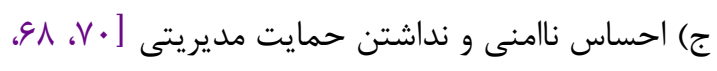

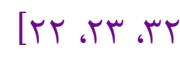
د) بررسىنكردن علت اصلى خطا [بr]

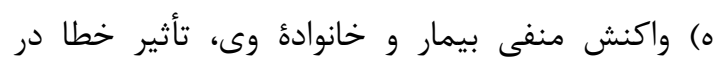

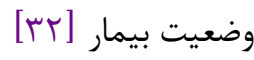
و) بار كارى سنخين ناشى از تعداد بسيار بيماران [بr]

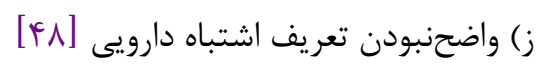

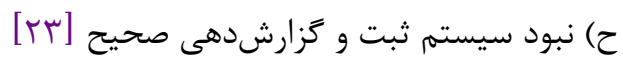

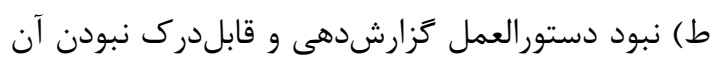

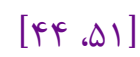
ى) تشويقنكردن بهدليل تزارشدهى [ارب].

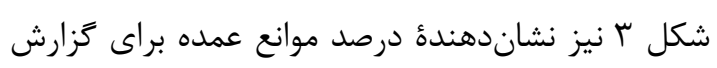

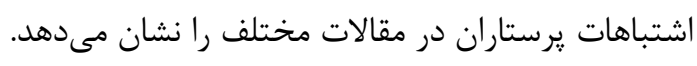

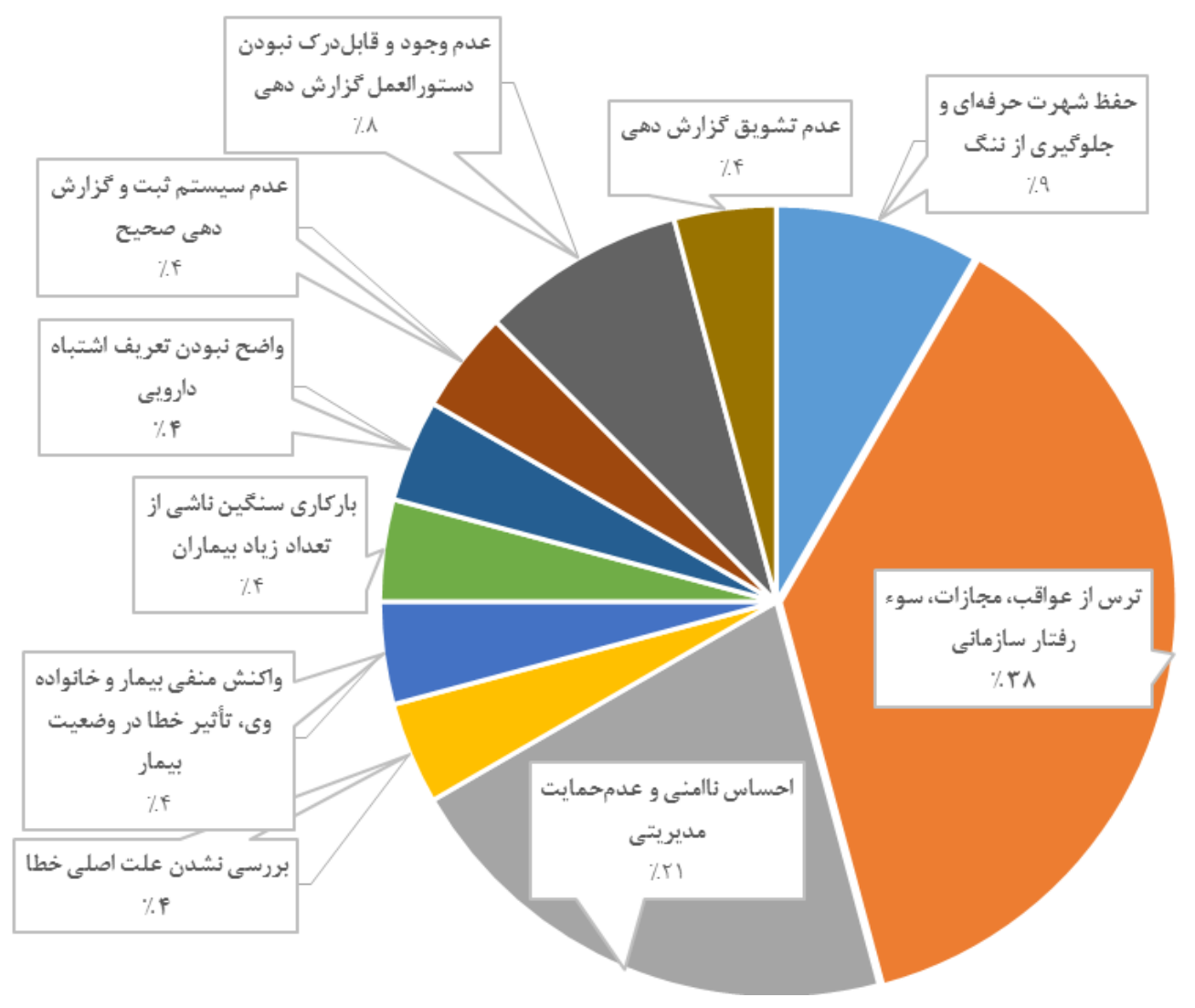

شكل r. درصد موانع عمده براى كزارش اشتباهات توسط برستاران در مقالات مختلف 
همجنين در ارتباط با جنبة مديريت شايعترين و كماهميتترين علل تعيينشده از سوى يرستاران بهترتيب عبارت است از: اسازماندهى نامناسب كاركنان يرستارى در واحد" و "انبود سياست مناسب مديريتى و دستورالعملها《. در ارتباط با آموزش و مهارت يرستاران، رايجترين و كمترين

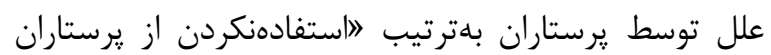

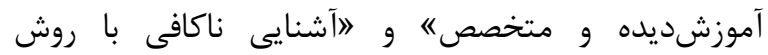
به كاركيرى تجهيزات هز زارش شده است. همجنين در ارتباط

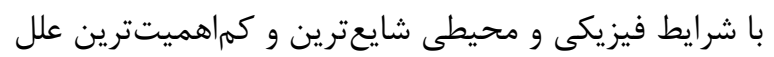
تعيينشده از سوى يرستاران بهترتيب لانامناسبوديون رفتار

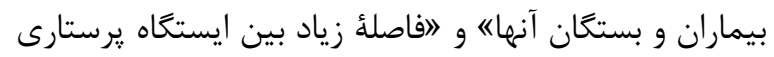

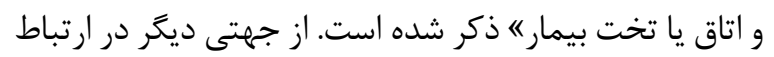
با هماهنكى تيم، بيشترين و كمترين علل از سوى يرستاران بلهترتيب لانامناسبودن روابط بين اعضاى تيم يرستارى" و

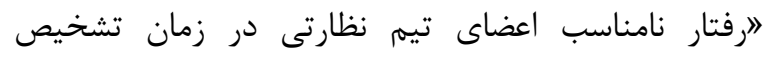

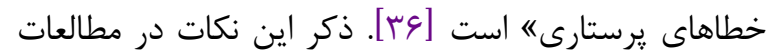
مختلف و آتاهى از آنها سبب مديريت صحيح براى كاهش عوامل ايجاد خطاهاى يرستاران در محيطهاى بهداشتى و و مراقبتى است. ^ץ درصد از مطالعات لاترس از عواقب، مجازات، سوء رفتار سازمانى" و 9 درصد از آنها لاحفظ شهرت حرفهاى و و جلوگيرى از ننَ" را دليل ززارشندادن خطا از سوى

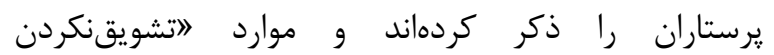
گزارشدهى"، لانبود سيستم ثبت و ززارشدهى صحيح"، "واضحنبودن تعريف اشتباه دارويى"، ابار كارى سنگين ناشى

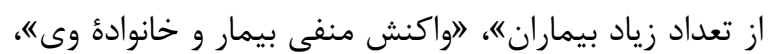

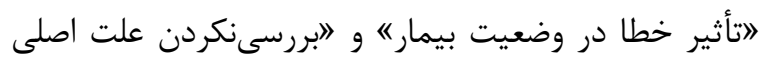
خطاه به يكميزان (F درصد) در مطالعات مختلف براى كزارشندادن گيرستاران ذكر شده است.

مديران بيمارستانها و بخشها نقش مهرمى در جلوكيرى

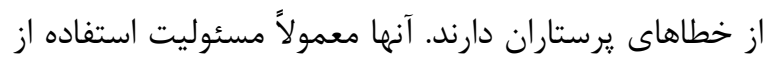

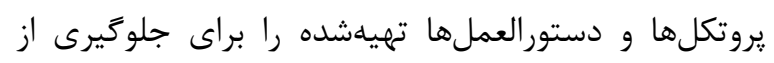
خطاهاى يرستاران بر عهده دارند [عس]. اولين كام در كاهش

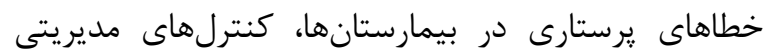
است؛ همانطور كه در مطالعه Wan به آن اشاره شده است [اץ[؛؛ زيرا براساس نتايج مطالعات متعدد، عواملى مانند كمبود نيروهاى يرستارى، بار كارى فراوان و توزيع نامناسب

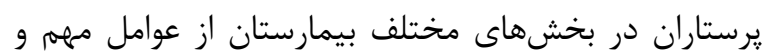

مطالعُ حاضر با هدف بررسى انواع، علل بروز خطاها در

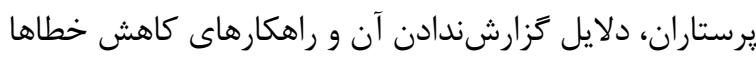
در مطالعات مختلف انجام شد. مطالعات مرورى در اين مطالعه

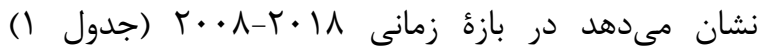
مطالعات داخل كشور در مقايسه با مطالعات خارج از كشور

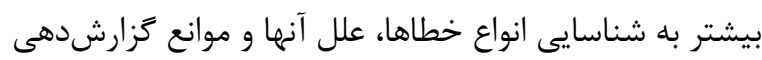

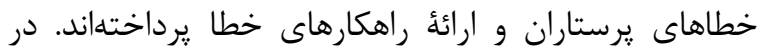

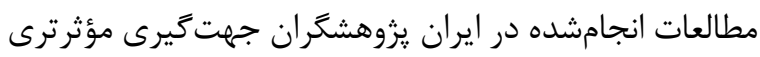
به بررسى علل خطا داشتهاند و كمتر به بررسى دلايل موانع

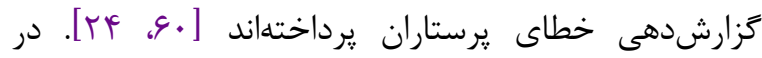

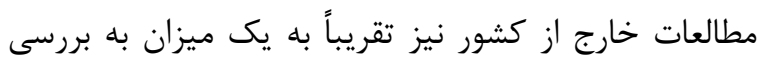

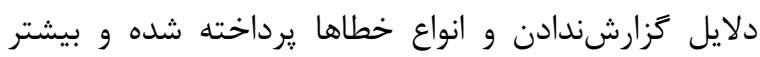
مطالعات در زمينهُ بررسى علل خطا بوده است [أل، سب، آ،

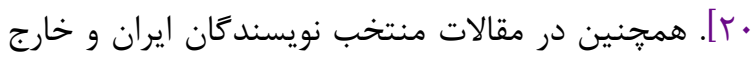

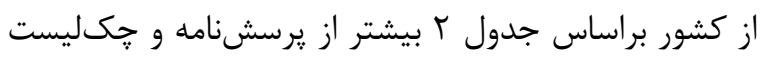

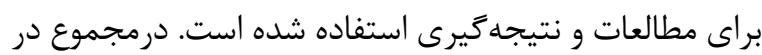
مطالعات آتى در داخل كشور و خارج از آن مىتوان به تحقيق بيشتر درباره دلايل ززارشندادن يرستاران يرداخت و حتى دانى

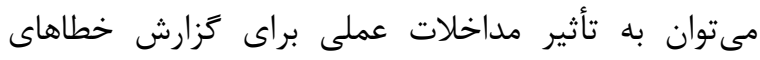
يرستاران مانند طراحى مطالعاتى از جمله ايجاد فرهنگَسازى مانى

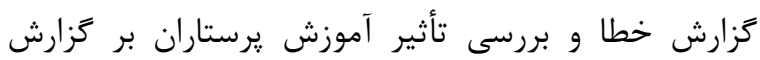
خطاهاى يرستارى «رداخت. براساس يافتههاى مطالعهُ حاضر (شكل بر ب)، بيشترين خطاهاى يرستارى شناسايىشده از نوع خطاهاى عملكردى

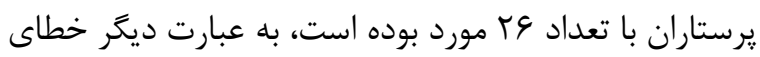

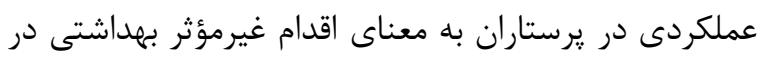
زمان و مكان مناسب بوده است. در اين ميان، تعدد وظايف از

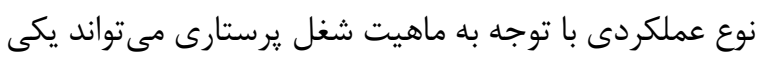

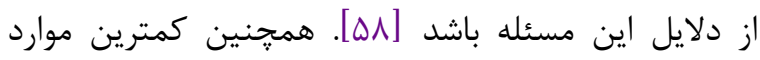
خطاها به خطاهاى بازيابى و انتخابى با تعداد أ مورد مربوط بوده است. در بروز خطا بهندرت مى توان عاملى منفرد رابى

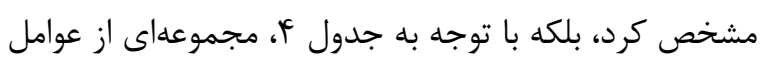

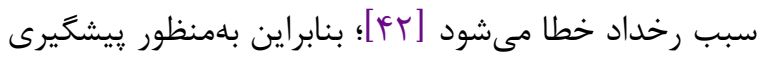

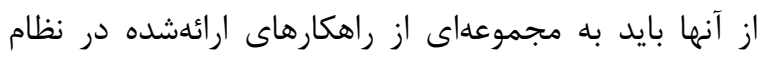
مديريت سلامت توجه كرد. در مطالعأ Zeighami و همكاران كه به بررسى علل خطاهاى يرستاران ڤيرداخته شده است، از نظر يرستاران بيشترين و كمترين دلايل خطاهاى يرستارى بلهترتيب مربوط به جنبئ مديريت و هماهنكى تيم بود. 
على صالحى سهل آبادى و همكاران | بررسى تأثير حمايت سازمانى ادراكشده در شكستن سكوت سازمانى با نقش ميانجى تعهد عاطفى

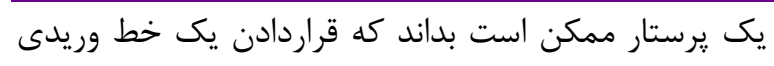

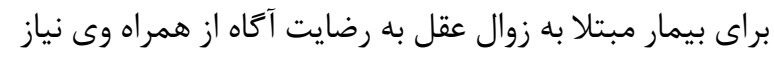

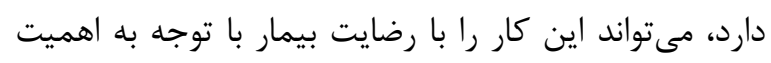

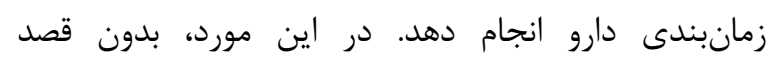

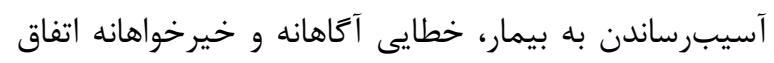

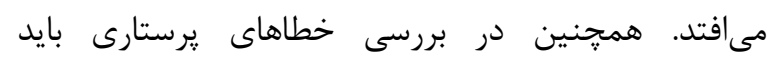

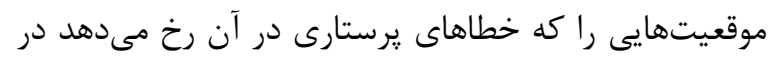

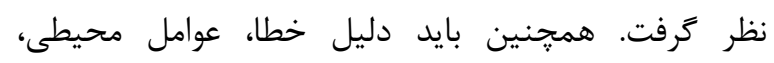

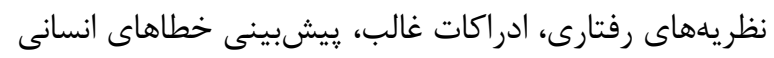
و نظريههاى اخلاقى را در نظر كرفت.

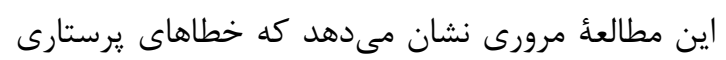

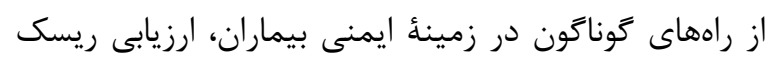

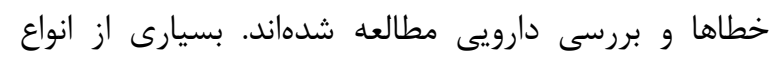

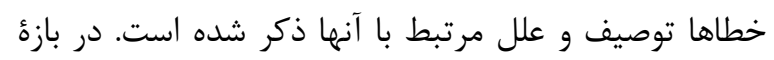

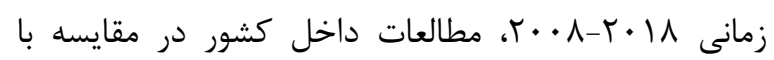

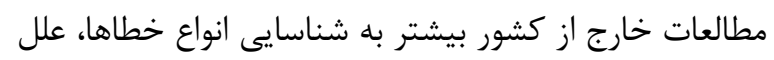

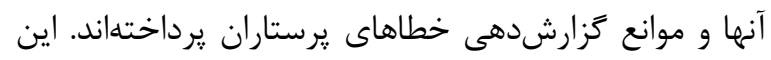

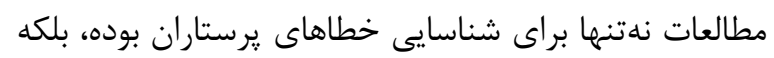

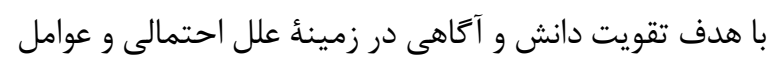

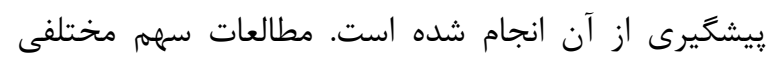

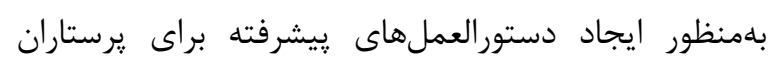

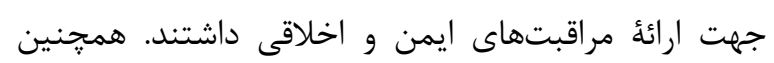

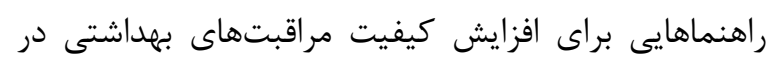

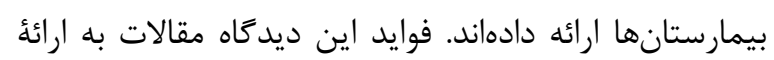

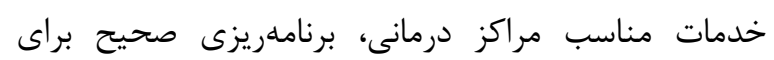

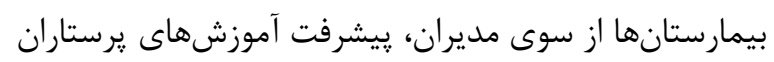

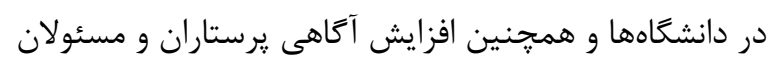

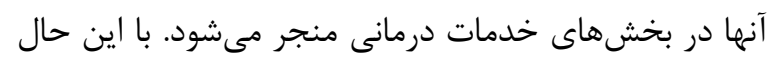

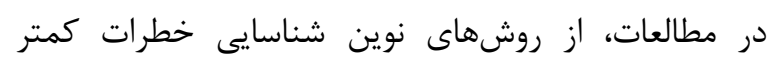

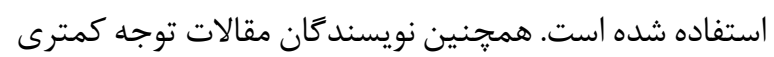

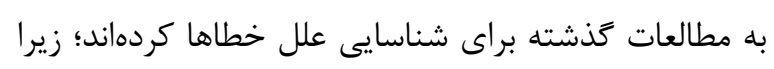

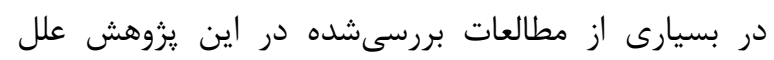

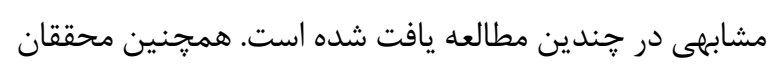

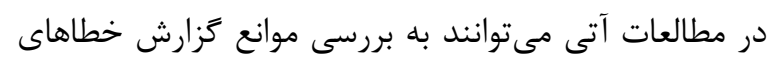

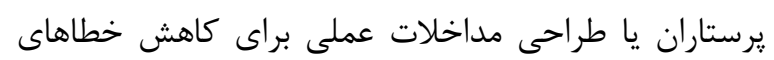

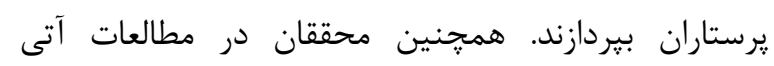

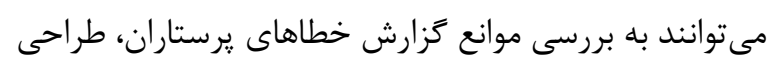

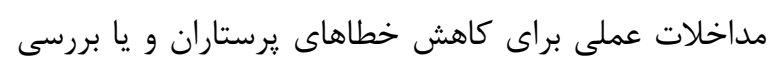

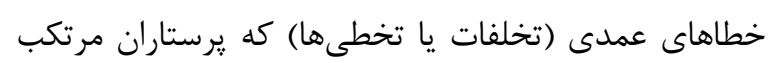

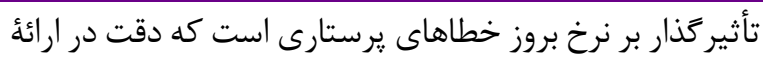

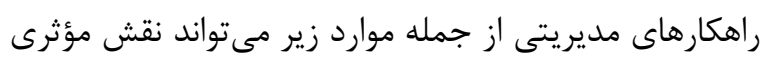

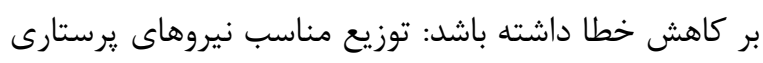

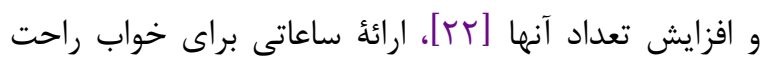

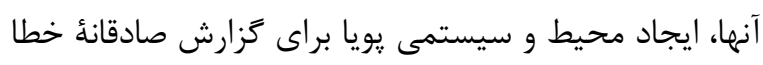

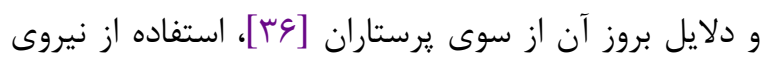

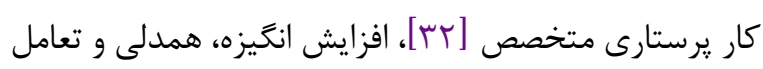

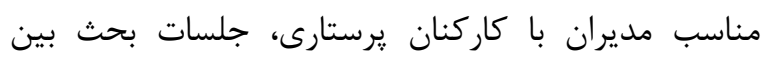

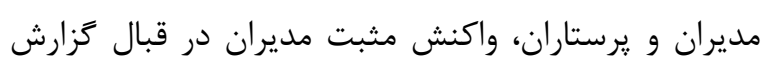

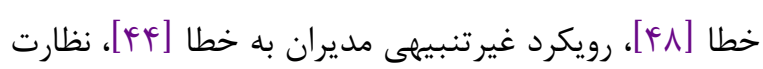

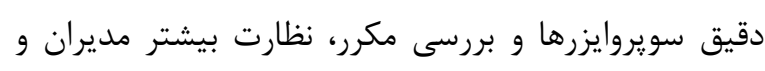

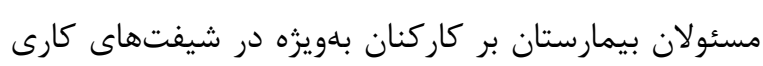

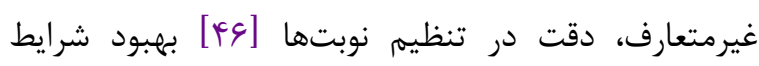

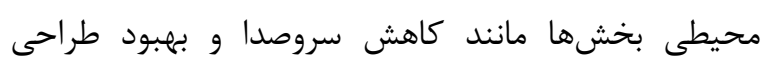
روشنايى [سب]. - محسئ. راهكار ديخرى كه Pazokian و همكاران بامنظور كاهش آنش

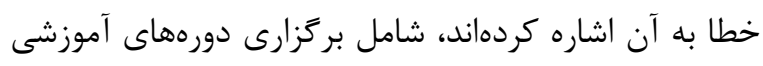

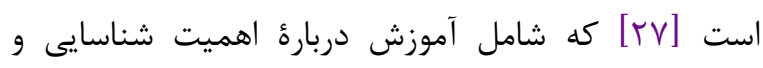

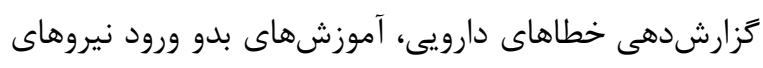

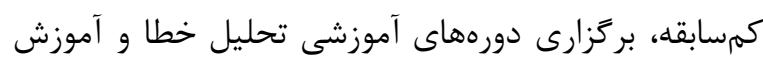

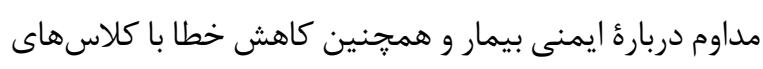

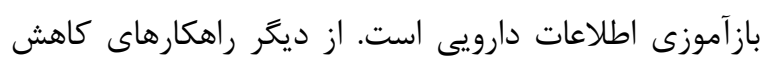

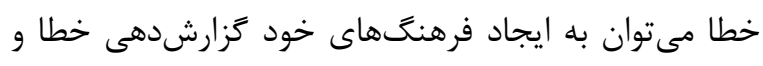

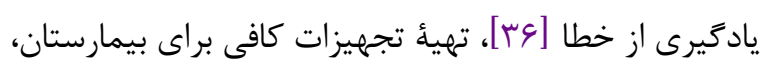

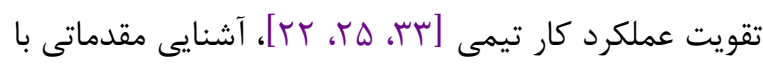

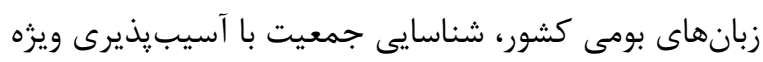

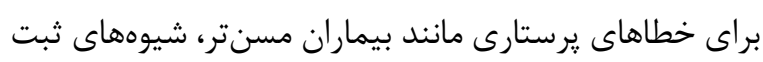

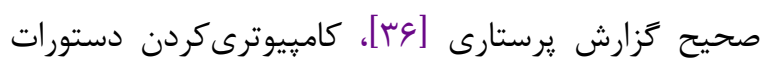

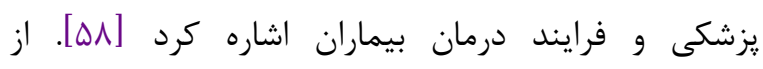

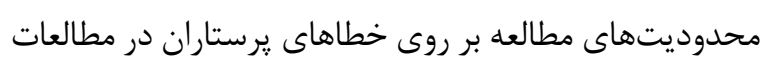
بررسىشده مىتوان به تمايلنداشتن كاركنان براى ترئ تكميل

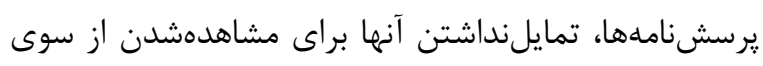

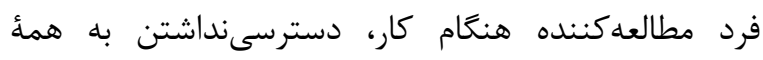

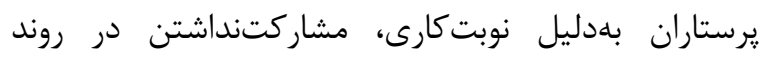

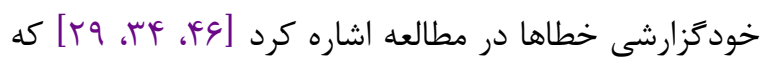

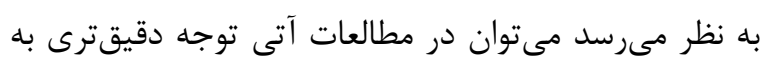

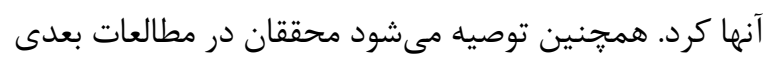

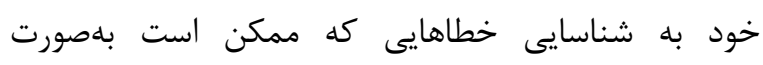
اشتباهات عمدى رخ دهد، بيردازند؛ براى مثال، درحالى كه 


$$
\begin{aligned}
& \text { فصلنامdٔ علمى يزوهشى اركونومى | دوره } 1 \text { شماره | | بهار 99با } \\
& \text { تقدير و تشكر } \\
& \text { نويسندگان مقاله از همكارانى كه در تفسير نتايج برخى } \\
& \text { از مطالعات كمك كردهاند، قدردانى مى كنند. } \\
& \text { تعارض منافع } \\
& \text { بين نويسندگًان هيجَّونه تعارضى در منافع وجود ندارد. }
\end{aligned}
$$

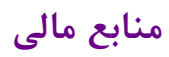

$$
\begin{aligned}
& \text { منابع مالى اين مطالعه توسط نويسندكان تامين شده است. } \\
& \text { شدهاند، بِردازند. با اين حال هنگَام مطالعات آينده بر روى } \\
& \text { خطاهاى يرستاران بايد موقعيتهايى را در نظر گرفت كه } \\
& \text { خطاهاى يرستارى در آن رخ مىدهند. يُ ئن } \\
& \text { نتيجه گيرى } \\
& \text { خطاهاى يرستارى از راههاى مختلف مطالعه شدهاند. اين } \\
& \text { مطالعات نهتنها براى شناسايى خطاهاى يرستاران بوده، بلكه }
\end{aligned}
$$

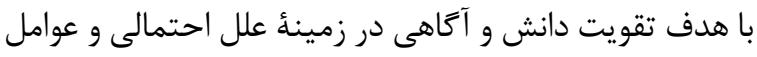

$$
\begin{aligned}
& \text { ״يشگيرى از آن انجام شده است. فوايد اين ديدگاه مقالات، به } \\
& \text { ارائٔ خدمات مناسب مراكز درمانى، برنامهريزى صحيح براى } \\
& \text { بيمارستانها از سوى مديران و ييشرفت آموزشهاى يرستاران } \\
& \text { منجر مىشود. }
\end{aligned}
$$

\section{References}

1. De Neef M, Bos AP, Tol D. Safety as a criterion for quality: the critical nursing situation index in paediatric critical care, an observational study. Intensive and Critical Care Nursing. 2009 Dec 1;25(6):341-7. [DOI:10.1016/j.iccn.2009.08.002] [PMID]

2. Durmus SÇ, Keçeci A, Akkas Ö, Keskin S, Demiral N, Saygan S. Medical errors: an important indicator of quality of care and patient safety. Holistic nursing $\begin{array}{llll}\text { practice. } & 2013 \quad \text { Jul 1;27(4):225-32. }\end{array}$ [DOI:10.1097/HNP.0b013e318294e6d3] [PMID]

3. Garrouste-Orgeas M, Philippart F, Bruel C, Max A, Lau $\mathrm{N}$, Misset B. Overview of medical errors and adverse events. Annals of intensive care. 2012 Dec 1;2(1):2. [DOI:10.1186/2110-5820-2-2] [PMID] [PMCID]

4. Tanaka K, Takahashi M, Hiro H, Kakinuma M, Tanaka M, Kamata N, Miyaoka H. Differences in medical error risk among nurses working two-and three-shift systems at teaching hospitals: a six-month prospective study. Industrial health. 2010;48(3):357-64. [DOI:10.2486/indhealth.48.357] [PMID]

5. Boluarte TA. The emotional impact of medical error involvement on physicians: a call for leadership and organizational accountability. Swiss medical weekly. 2009 Jan 10;139(0102).

6. Martinez W, Lo B. Medical students' experiences with medical errors: an analysis of medical student essays. Medical education. 2008 Jul;42(7):733-41. [DOI:10.1111/j.1365-2923.2008.03109.x] [PMID]

7. Valiee S, Peyrovi H, Nikbakht Nasrabadi A. Critical care nurses' perception of nursing error and its causes: A qualitative study. Contemporary nurse. 2014 Feb 1;46(2):206-13. [DOI:10.5172/conu.2014.46.2.206] [PMID]

8. Lewis EJ, Baernholdt M, Hamric AB. Nurses' experience of medical errors: An integrative literature review. Journal of Nursing Care Quality. 2013 Apr 1;28(2):153-61. [DOI:10.1097/NCQ.0b013e31827e05d1] [PMID]

9. Keepnews DM. Mapping the economic value of nursing. Commissioned by the WSNA Professional Nursing \& Health Care Council Washington State Nurses Association. June. 2011;6.

10. Haugen AS, Sevdalis N, Søfteland E. Impact of the world health organization surgical safety checklist on patient safety. Anesthesiology: The Journal of the American Society of Anesthesiologists. 2019 Aug 1;131(2):420-5. [DOI:10.1097/ALN.0000000000002674] [PMID]

11. Nouhi E, Dehbanizadeh A, Zoladl M, Saeedi KH, Paghan A. Error Reporting among Nurses Working at Yasuj Shahid Beheshti Hospital in 2014. Iran Journal of Nursing. 2016 Aug;29(101):33-42. [DOI:10.29252/ijn.29.101.33]

12. Crigger NJ, Meek VL. Toward a theory of selfreconciliation following mistakes in nursing practice. Journal of Nursing scholarship. 2007 Jun;39(2):177-83. [DOI:10.1111/j.1547-5069.2007.00164.x] [PMID]

13. Jember A, Hailu M, Messele A, Demeke T, Hassen M. Proportion of medication error reporting and associated factors among nurses: a cross sectional study. BMC nursing. 2018 Dec;17(1):9. [DOI:10.1186/s12912-0180280-4] [PMID] [PMCID]

14. Sanagoo A, Majnoni MZ, Jouybari LM, Ghana S, Kalantari S. Studying the nursing students experiences of clinical errors and dealing with them.

15. Madadi Z, Jaafaripooyan E. Nursing Medication Errors, Causes and Solutions. J of Hospital. 2015;3(14):101-9.

16. JALALIFAR F, SEPEHRI MM. Medication process analytics, errors recognition, and contributory factors in creation of the errors.

17. Keers RN, Williams SD, Cooke J, Ashcroft DM. Prevalence and nature of medication administration errors in health care settings: a systematic review of direct observational evidence. Annals of Pharmacotherapy. 2013 Feb;47(2):237-56. [DOI:10.1345/aph.1R147] [PMID] 
18. Kiekkas P, Karga M, Lemonidou C, Aretha D, Karanikolas M. Medication errors in critically ill adults: a review of direct observation evidence. American Journal of Critical Care. 2011 Jan;20(1):36-44. [DOI:10.4037/ajcc2011331] [PMID]

19. Flynn EA, Barker KN, Pepper GA, Bates DW, Mikeal RL. Comparison of methods for detecting medication errors in 36 hospitals and skilled-nursing facilities. American Journal of Health-System Pharmacy. 2002 Mar 1;59(5):436-46. [DOI:10.1093/ajhp/59.5.436] [PMID]

20. Chen LC, Wang LH, Redley B, Hsieh YH, Chu TL, Han CY. A Study on the reporting intention of medical incidents: A nursing perspective. Clinical nursing research. $2018 \quad$ Jun;27(5):560-78. [DOI:10.1177/1054773817692179] [PMID]

21. Wan QJJoN. Analysis and Countermeasures on 195 Cases of Adverse Events in Nursing Care. 2015;4(4):12-4. [DOI:10.18686/jn.v4i4.4]

22. Ebrahimipour H, Hosseini E, Haghighi H, Tabatabaee SS, Badiee S, Vafaee Najar A, Mahmoudian P. Evaluation of medication errors by nurses in hospitals affiliated with Mashhad University of Medical Sciences, Mashhad, Iran. Journal of Patient Safety \& Quality Improvement. 2016;4(3):400-4.

23. Peyrovi H, Nikbakht Nasrabadi A, Valiee S. Exploration of the barriers of reporting nursing errors in intensive care units: A qualitative study. Journal of the Intensive Care Society. $2016 \quad$ Aug;17(3):215-21. [DOI:10.1177/1751143716638370] [PMID] [PMCID]

24. Askari R, Shafii M, Rafiei S, Abolhassani MS, Salarikhah E. Failure mode and effect analysis: improving intensive care unit risk management processes. International Journal of Health Care Quality Assurance. 2017 Apr 18. [DOI:10.1108/IJHCQA-04-2016-0053] [PMID]

25. Adibi H, Saeedi M. Medical adverse events: Root cause analysis of 16 reports from a teaching hospital. Payesh (Health Monitor). 2016 Dec 15;15(6):629-37.

26. Mohammadfam I, Movafagh M, Soltanian A, Salavati M, Bashirian S. Assessment of human errors in the nursing profession of intensive cardiac care unit using SPAR-H method.

27. Pazokian M, Zaghari Tafreshi M, Rassouli M, Zayeri F. Testing Nurses' Medication Errors Model based on Reason Human Error Model. Iran Journal of Nursing. 2013 Dec;26(85):1-4.

28. Babaeipouya A, Mosavianasl Z, Amani S, Moazez Ardebili N. Human error analysis in neonatal intensive care unit by predictive analysis of cognitive errors. J Occup Environ Health. 2017 Apr 10;3(1):38-47.

29. Roth C, Wieck KL, Fountain R, Haas BK. Hospital nurses' perceptions of human factors contributing to nursing errors. JONA: The Journal of Nursing Administration. 2015 May 1;45(5):263-9. [DOI:10.1097/NNA.0000000000000196] [PMID]

30. Mostafa MA, Iraj M, Ali Reza S, Mehran G, Mahnoush $\mathrm{K}$. Identification, assessment and control of errors in chemotherapy process: A Case Study among physician and nurse. International Journal of Occupational Hygiene. 2017 Dec 1;9(4).
31. Foo GT, Tan CH, Hing WC, Wu TS. Identifying and quantifying weaknesses in the Closed Loop Medication Management System in reducing medication errors using a direct observational approach at an academic medical centre. Journal of Pharmacy Practice and Research. 2017 Jun;47(3):212-20. [DOI:10.1002/jppr.1235]

32. Winsett RP, Rottet K, Schmitt A, Wathen E, Wilson D, Group MN. Medical surgical nurses describe missed nursing care tasks-Evaluating our work environment. Applied Nursing Research. 2016 Nov 1;32:128-33. [DOI:10.1016/j.apnr.2016.06.006] [PMID]

33. Feleke SA, Mulatu MA, Yesmaw YS. Medication administration error: magnitude and associated factors among nurses in Ethiopia. BMC nursing. 2015 Dec 1;14(1):53. [DOI:10.1186/s12912-015-0099-1] [PMID] [PMCID]

34. Alemu W, Belachew T, Yimam I. Medication administration errors and contributing factors: A cross sectional study in two public hospitals in Southern Ethiopia. International journal of Africa nursing sciences. 2017 Jan 1;7:68-74. [DOI:10.1016/j.ijans.2017.09.001]

35. Fathi A, Hajizadeh M, Moradi K, Zandian H, Dezhkameh M, Kazemzadeh S, Rezaei S. Medication errors among nurses in teaching hospitals in the west of Iran: what we need to know about prevalence, types, and barriers to reporting. Epidemiology and health. 2017;39. [DOI:10.4178/epih.e2017022] [PMID] [PMCID]

36. Zeighami R, Shokati Ahmadabad M, Mohammadian A, Alipoor Heydari M, Rafiei H. Nursing errors and effect on health care: Perception of risk factors from view of nurse in Qazvin. International Journal of Epidemiologic Research. 2016 Feb 1;3(1):26-32.

37. Bravo K, Cochran G, Barrett R. Nursing strategies to increase medication safety in inpatient settings. Journal of nursing care quality. 2016 Oct 1;31(4):335-41. [DOI:10.1097/NCQ.0000000000000181] [PMID]

38. Samsiah A, Othman N, Jamshed S, Hassali MA. Perceptions and attitudes towards medication error reporting in primary care clinics: a qualitative study in Malaysia. PLoS One. 2016 Dec 1;11(12):e0166114. [DOI:10.1371/journal.pone.0166114] [PMID] [PMCID]

39. Weaver AL, Stutzman SE, Supnet C, Olson DM. Sleep quality, but not quantity, is associated with self-perceived minor error rates among emergency department nurses. International emergency nursing. 2016 Mar 1;25:48-52. [DOI:10.1016/j.ienj.2015.08.003] [PMID]

40. Morelock S. Sustained vigilance and errors in critical care. Nursing2019 Critical Care. 2016 Nov 1;11(6):38-47. [DOI:10.1097/01.CCN.0000503414.59852.16]

41. Nwozichi CU. Why are chemotherapy administration errors not reported? Perceptions of oncology nurses in a Nigerian tertiary health institution. Asia-Pacific journal of oncology nursing. 2015 Jan;2(1):26. [DOI:10.4103/23475625.152403] [PMID] [PMCID]

42. Ajri-Khameslou M, Abbaszadeh A, Borhani F, Farokhnezhad Afshar P. Contributing factors to nursing error in emergency department: A qualitative study. Journal of hayat. 2017 Apr 10;23(1):17-32 
43. Bozorgzad M, Hemati Z. Frequency of errors in nursing and associated factors in the cases referred to the Mortality Committee in Shahrekord University of Medical Sciences during 2006-2012. Journal of Clinical Nursing and Midwifery. 2015;4.

44. Zaboli R, Ghiasi AR. Identifying barriers of self-reported error by nurses in polices hospitals. Journal of Police Medicine. 2016 Mar 10;4(4):235-44.

45. Shali M, Joolaee S, Hooshmand A, Haghani $H$. Committed Nurse: This Patient is wrong. Medical Ethics Journal. 2016 Jan 1;10(34):11-30.

46. Mohammadfam I, Movafagh M, Soltanian A, Salavati M, Bashirian S. Identification and evaluation of human errors among the nurses of coronary care unit using CREAM techniques. Iranian Journal of Ergonomics. 2014 Jun 10;2(1):27-35.

47. Saki K, Khezri_Azar J, Mohebbi I. Nursing errors and its relationship with fatigue among nurses of the emergency ward. Journal of Urmia Nursing And Midwifery Faculty. 2016 Jan 10;13(10):835-42.

48. Hesari B, Ghodsi H, Hoseinabadi M, Chenarani H, Ghodsi A. A survey of nurses' perceptions of the causes of medication errors and barriers to reporting in hospitals affiliated to Neyshabur university of medical sciences, Iran. Journal of kerman university of medical sciences. 2015 Jan 1;21(1):105-11.

49. Nooreddini A, Sanagoo A, Jouybari L, Okhli A, Gholam Hosein Nataj A. Survey Factors affecting medication errors and influencing status reporting of nurses viewpoint $\% \mathrm{~J}$ nursing development in health. 2017;8(1):17-27.

50. Wu Q, Zhu XP, Gong MF, Tian MM, Zeng L, Liu XL, Zhang L, Shi Y. Effect of an inpatient nursing risk early warning and control system in Shanghai: A retrospective study of adverse events. International Journal of Nursing Sciences. 2015 Jun 1;2(2):190-4. [DOI:10.1016/i.ijnss.2015.05.003]

51. Kohan AD, Mahfoozpour S, Palesh M, Ouchhesar FF. Assessing barriers to medical errors reporting among clinical staff members of teaching hospitals affiliated with Shahid Beheshti University of Medical Sciences in Tehran-2016. Journal of Health in the Field. 2018;5(3).

52. Mohsenpour M, Hosseini M, Abbaszadeh A, Shahboulaghi FM, Khankeh H. Nursing error: an integrated review of the literature. Indian J Med Ethics. 2017 Apr;2(2):75-81. [DOI:10.20529/IJME.2017.020]

53. Forte EC, Pires DE, Padilha MI, Martins MM. Nursing errors: a study of the current literature. Texto \& ContextoEnfermagem. 2017;26(2). [DOI:10.1590/010407072017001400016]

54. Baghaei R, Khalkhali HR, Nadari Y. Evaluation of predisposing factors of nursing errors in critical care units of urmia medical science university hospitals. The Journal of Urmia Nursing and Midwifery Faculty. 2012;10(3):312-20
55. Eslamian J, Taheri F, Bahrami M, Mojdeh S. Assessing the nursing error rate and related factors from the view of nursing staff. Iranian journal of nursing and midwifery research. 2010 Dec;15(Supp11):272.

56. Wilkinson WE, Cauble LA, Patel VL. Error detection and recovery in dialysis nursing. Journal of patient safety. 2011 Dec 1;7(4):213-23. [DOI:10.1097/PTS.0b013e3182388d20] [PMID]

57. Habermann M, Foraita R, Cramer H. Categories of errors and error frequencies as identified by nurses: results of a cross-sectional study in German nursing homes and hospitals. Journal of Public Health. 2013 Feb 1;21(1):313. [DOI:10.1007/s10389-012-0531-x] [PMID]

58. Kermani A, Mazloumi A, NaslSeraji J, GhasemZadeh F. Identification and evaluation of human errors using SHERPA technique among nurses at emergency ward of an educational hospital in Semnan city, Iran. Occupational Medicine Quarterly Journal. 2013 Feb 1;4(4):29-43.

59. Hashemi F. Ethical response to nursing error\%J Journal of Medical Ethics and History of Medicine. 2008;1(4):31-46.

60. Scott SD, Hirschinger LE, Cox KR, McCoig M, Brandt J, Hall LW. The natural history of recovery for the healthcare provider "second victim" after adverse patient events. BMJ Quality \& Safety. 2009 Oct 1;18(5):325-30. [DOI:10.1136/qshc.2009.032870] [PMID]

61. Green M. Nursing error. Nursing Law. 2009;9:37-44.

62. Ghiyasi S, Heidari M, Hoda A, Azimi L. Human error risk assessment of clinical care in emergency department with SHERPA approach and nurses safety climate analysis. Iran Occupational Health. 2018 Aug 10;15(3):129-40.

63. Ghorbanpour Diz M, Mohammad khan Kermanshahi S, Sedaghat M. Evaluation of self-report of the medication errors and its barriers in pediatric wards. Journal of Pediatric Nursing. 2016 Sep 15;3(1):71-80. [DOI:10.21859/ipen-0301106]

64. Rahimi F, Ahangar zadeh Rezaei S, Baghaei R, Faezi A. Factors affecting the incidence of medication errors in nursing staff of Besat Hospital in Sanandaj City in 2011. Scientific Journal of Nursing, Midwifery and Paramedical Faculty. $2016 \quad$ Feb 10;1(3):12-7. [DOI:10.29252/sjnmp.1.3.2]

65. Nouhi E, Mohamadi M, Abbaszadeh A. Barriers to error reporting and preventive strategies from viewpoints of nursing staff in social security hospitals in Kerman. Iran Journal of Nursing. 2015 Dec;28(97):56-65. [DOI:10.29252/ijn.28.97.56]

66. Ahangarzadeh Rezaei S, Baghaei R, Feizi A, Rahimi F. A survy on the nursing-related factors influencing medication error incidence. The Journal of Urmia Nursing and Midwifery Faculty. 2014;12(12):1088-93.

67. Mirzaei M, Khatony A, Faramani RS, Sepahvand E. Prevalence, Types of Medication errors and Barriers to Reporting Errors by Nurses in an Educational Hospital in Kermanshah. Hayat. 2013 Jul 1;19(3). 
68. Salavati S, Hatamvand F, Tabesh H. Nurses' Perspectives on Causes of Medication Errors and Non-Reporting at ED. Iran journal of nursing. 2012 Dec;25(79):72-83.

69. Soori S, Rostami Z, Aghilidehkordi G. Occurrence and reporting of nurses' medication errors in a teaching hospital in Isfahan. Journal of Health Administration. 2019 Jan 10;21(74):75-86. [DOI:10.29252/jha.21.74.75]

70. Azarabad S, Zaman SS, Nouri B, Valiee S. Frequency, causes and reporting barriers of nursing errors in the operating room students. Research in Medical Education. 2018 Jul 10;10(2):18-27. [DOI:10.29252/rme.10.2.18] 